العوامل المرتبطة بتقدير الأت لاي عينة من الأطفال في مرحلة الطفولة المتأخرة

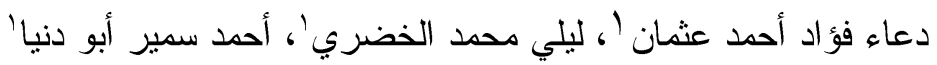

- أظهرت النتائج أيضاً أن جميع الأطفال المبحوثين قد تعرضوا

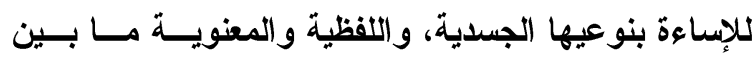

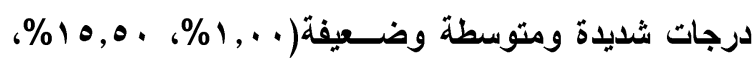

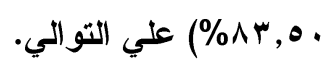

- أظهرت النتائج أن צr, . ه\% و ؟ه\% من الأطفال المبحوثين

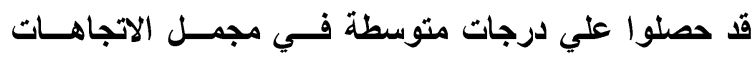

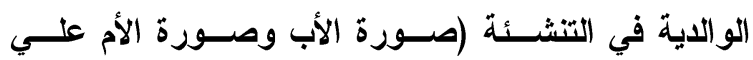

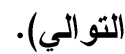

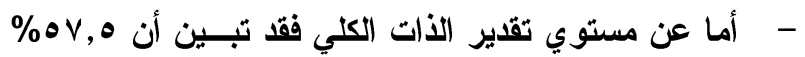
من الأطفال المبحوثين كان مستوي تقايرهم الكلي لـذاو اتهم

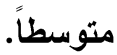

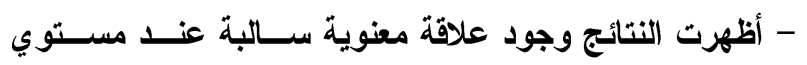
ال. , • بين جنس الطفل وتقاير الذات الكلي، وعلاقة معنوية

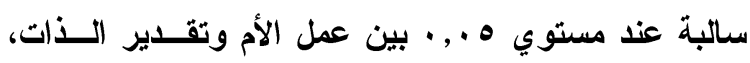
كنلك وجدت علاقة معنوية موجبة عند مستوي ه ه. ., ب بين المستوي التعليمي للأب وتقلير الطفل لذاته.

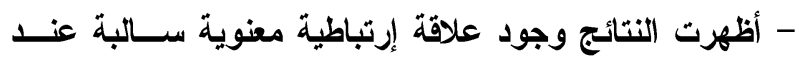

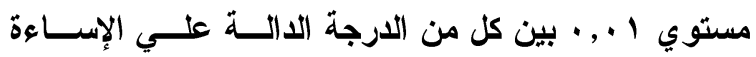

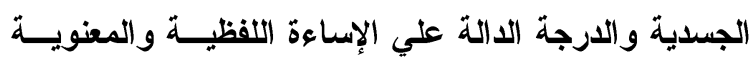
و الدرجة الدالة علي مجمل الإساءة التي يتعرض لها الطاءئل الطفل وتقبيره لذاته.

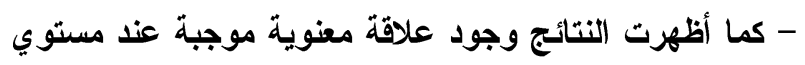
ه ., · بين الإتجاهات الو الدية (صورة الأب) وتقدير الطفل

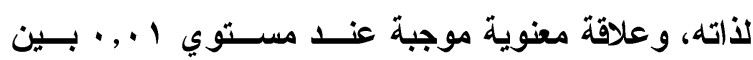
الإتجاهات الو الاية (صورة الأم) وتقدير الطفل لذاته. الكلمات المفتاحية: تقلير الأات، الإساءة للطفل.

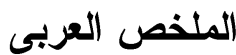

يهذف البحث بصفة رئيسية إلي دراسة العوامل المرتبطـة بتقير الذات بين عينة من الأطفال في مرحلة الطفولة المتأخرة،

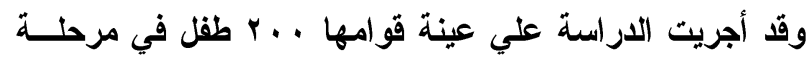

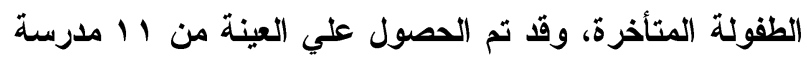

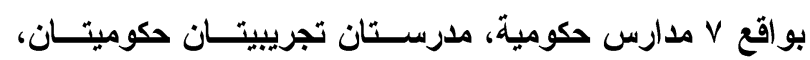

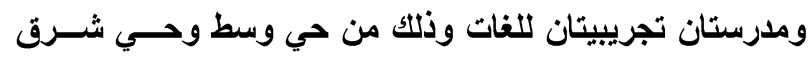

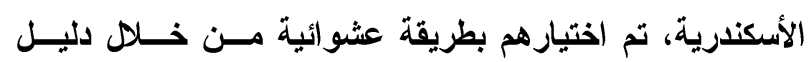
المارس الخاص بححافظة الأسكندرية من خلا موقع الانترنت الخاص بوزارة الثربية والتعليم.

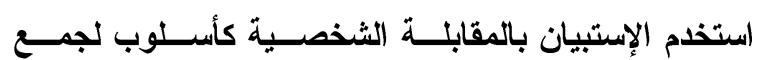

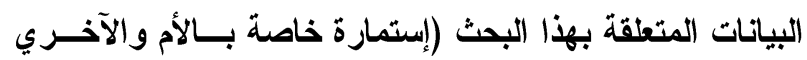
خاصة بالطفل). ومن أهم النتائج التي أسفرت عنها الدراسة:

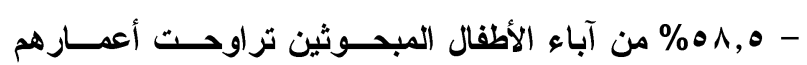

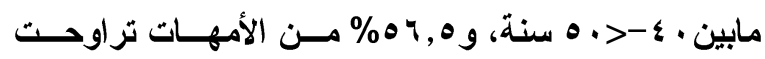

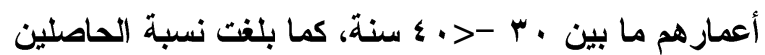

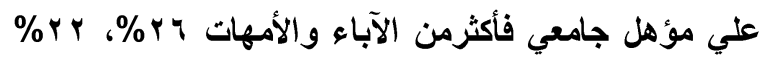

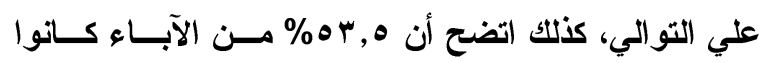

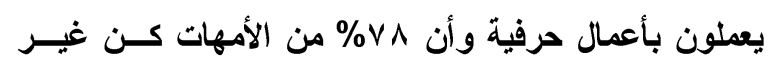

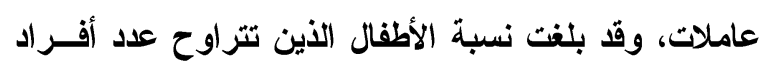

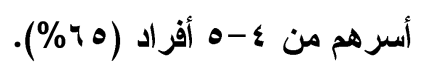

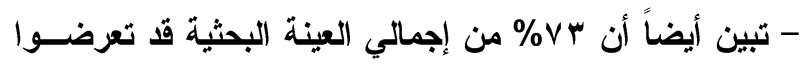

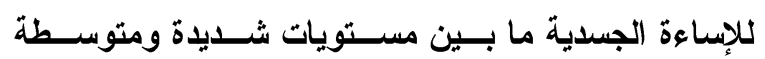

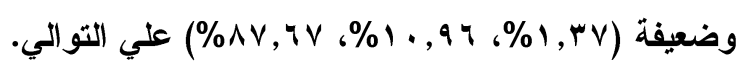
- كما تبين أن جميع الأطفال المبحوثين قد تعرضـــوا للإِـــاءة

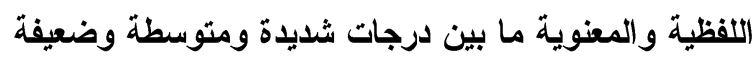

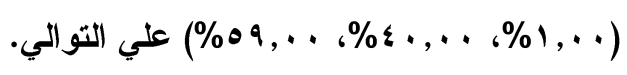

'قسم الاقتصاد المنزلي كلية الزر اعة-الثناطبي- جامعة الإسكندرية

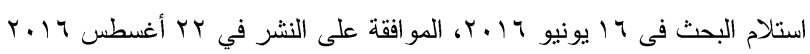


مجلة الإسكندرية للتبادل العلمى - (مجلد Tr العددץ) يوليو - سبتمبر 17 • ب

بانخفاض تقدير الذات، فهذا الثعور الذي يحمله الأطفال نحو

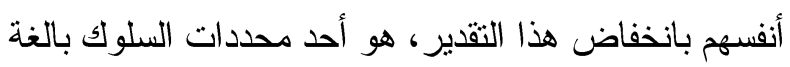

$$
\text { الأهمية (عبد ربه شعبان، • 1 • ب). }
$$

\section{المشكلة البحثية}

هناك العديد من العوامل المؤثرة علي تقدير الطفل لذاته،

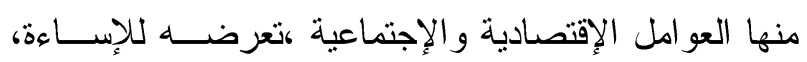
و الاتجاهات الو الدية في التنشئة.

فالإساءة أصبحت من الظو اهر الاجتماعية الخطيرة التي

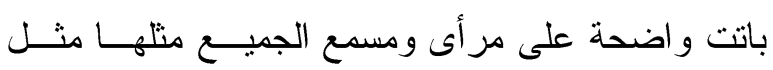
الظواهر الإجتماعية المنتشرة والتي تعتبر من الســلـوكيات الخطيرة مما لها من آثار إجتماعية ونفسية سيئة و لا يمكن قبولها في أي مجتمع بشري وخاصة المجتمعات التي تمتاز

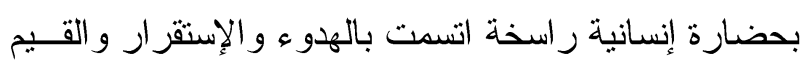

$$
\text { (علي أبو زهري وآخرون، ^ ... ب). }
$$

ويتفق معظم العلماء على أن الإساءة ليست بالظــاهرة

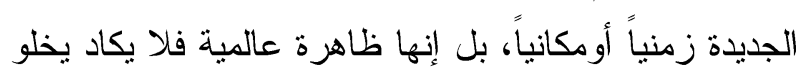

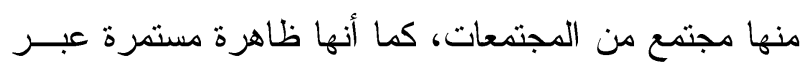
التاريخ لم يخل منها حقبة تاريخية منذ أن خلــق الإنســان وحتي وقتتا الر اهن (تهاني منيب وعزة سليمان، ل . . Y).

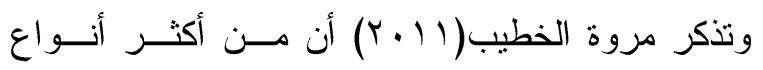

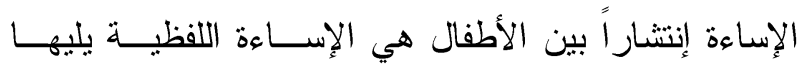

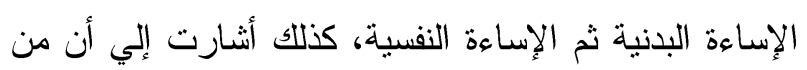
أهم اسباب إنتشار ظاهرة الإساءة تلك المتعلقة بالو الدين، ثم الأسباب الإقتصادية و أخيراً الأسباب الثقافية. ومن خلال الدراسة التي أجراها المجلس القومي للطفولة

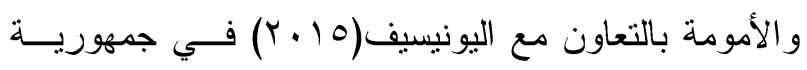

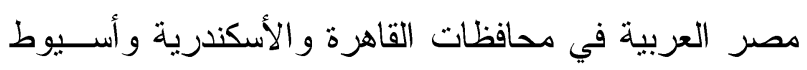
تبين أن حو الي مV م من الأطفال في المناطق التي شملتها

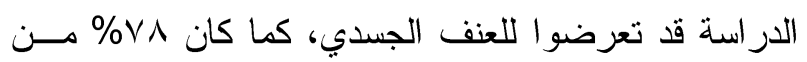
إجمالي الأطفال ضحايا للعنف النفسي.

\section{المقدمة}

يري علماء النفس أن الأطفال لا يولدون بتقدير مرتفــع

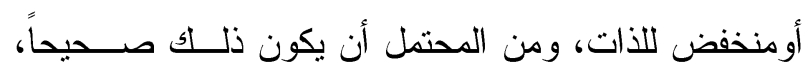
ولكن من المؤكد أن تقدير الذات يتطور بصورة تدريجيـة

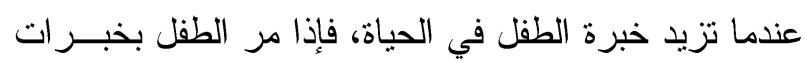

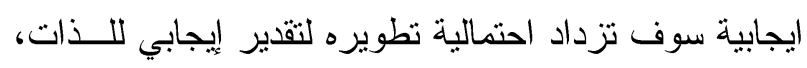
و علي العكس عندما يتلقي خبرات سلبية يمكن أن ينمو لديه

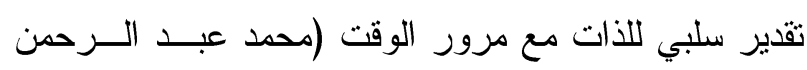
ومني حسن، ب... (r).

كما يعتبر تقدير الذات من المفاهيم التي اتجـــه العلمـــاء لدر استها في السنو ات الأخيرة، حيث تعتبر عاملاً هاماً وفعالاً في تو افق الفرد وصحته النفسية، وقد اعتبر" ماسلو" الحاجة إلي تقدير الذات من الحاجات الأساسية للإنسان و أيده في ذلك

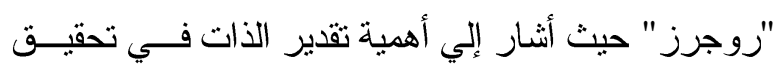
التو افق و الرضا النفسي (أميرة السيد، V. . . Y). إن من نعم الله عز وجل على الآباء نعمة الأبناء، وما من

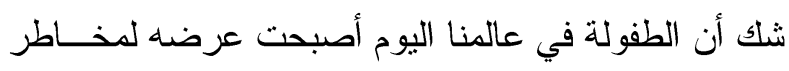
عديدة، إذ تستوجب ر عاية خاصة من قبل الو الدين، فالأسـرة تشكل البيئة الأولي للتنشئة و التطبيع، وهي خط الدفاع الأول

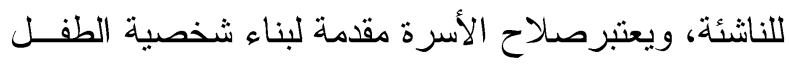
على أسس سليمة، فقد تضافرت جهود علماء النفس في در اسة الحاجات النفسية للأفر اد في مر احل العمر المختلفة، وذلك من أجل فهم وتفسير سلوكهم ومساعدتهم على إثباع حاجــاتهم

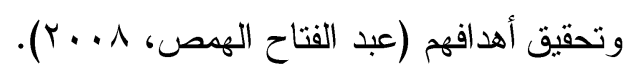

ويبدأ الأطفال بتكوين إتجاهاتهم نحــو أنفسـهـم عنــدما

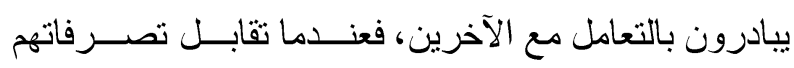

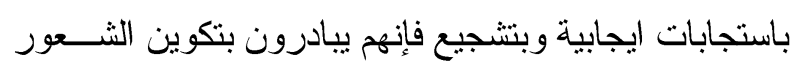

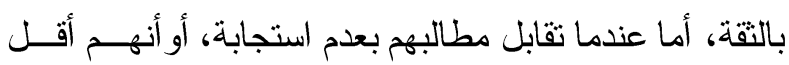

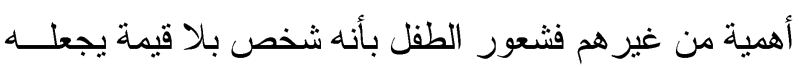

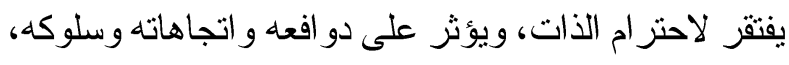
و الكثير من مشكلات الطفولة المبكرة تتجم عـن الثــعور 


\section{أهداف البحث}

يهدف البحث بصفة رئيسية إلي در اســـة العلاقــة بــين

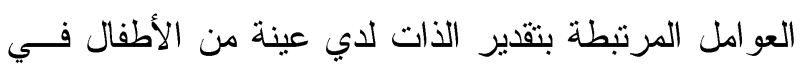
مرحلة الطفولة المتأخرة.

وينبثق من هذا الهدف الرئيسي الأهداف الفرعية التالية: 1- در اسة الخصائص الثخصية والأسرية للعينة البحثية. Y - تحديد أنماط وشدة الإساءة التي يتعرض لها الطفل. س- قياس درجة تقدير الأطفال المبحوثين لذو اتهم. ع - در اسة الإتجاهات الوالدية في التنشئة كما ير اها الأبناء. 0- دراسة العلاقة الإرتباطيــة بــين بعـضـ الخصـــائص الشخصية و الأسرية و تقدير الأطفال لذو اتهم.

1- در اسة العلاقة الإزتباطية بين الدرجــة الدالـــة علــي الإساءة الموجهة للطفل وتقديره لذاته.

- V العلاقة بين الإتجاهات الوالدية في التنشئة كما براها الأبناء وتقدير هم لذو اتهم.

طرق البحث أولاً: التعريفات الإجر ائية

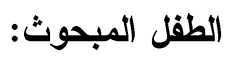

يعرف الطفل إجرائياً في هذه الدراسة علي أنه الطفــلـ

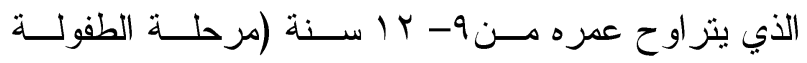
المنأخرة) و الملتحق بالمدرسة الإبتدائية و الذي يعيش داخل أسرة.

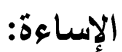

ويقصد بالإساءة في هذه الدراسة هي كل سلوك ضـــار

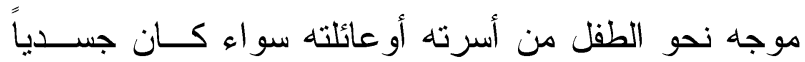
أومعنوياً أولفظياً، ويسبب هذا السلوك أذي للطفل.
كذلك كثف التحليل الإحصائي للعنف ضد الأطفال الذي

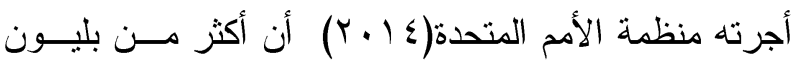

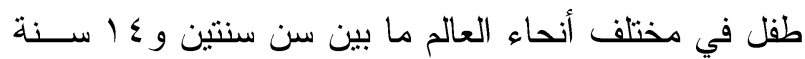
يعانون من الإساءة الجسدية، كما أن واحدة من كل ع فتيات ما بين سن 10-9 19 سنة يتعرضن لها.

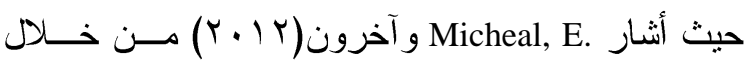

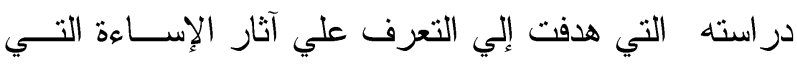
يتعرض لها بعض الطلاب الذكور في الولايــات المتحــدة

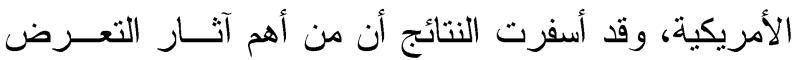
للإساءة هي انخفاض تقدير الذات عند هؤلاء الأطفال حيث

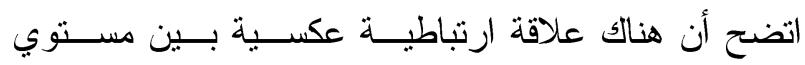
التعرض للإساءة وتقدير الذات.

وتعد الأسرة ذات أهمية كبيرة فــى تشــكيل شخصــية الطفل، فالأسرة هي النواة الأولي التي ينشأ فيها الفرد، كما

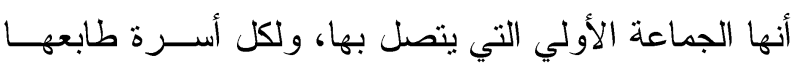
المميز وصفاتها و وتقاليدها و عاداتها وسلوكياتها التي تجعلها تحيط بالأفر اد بحياة تختلف عن غير هم من بقية الأفر اد فى وهي وهي

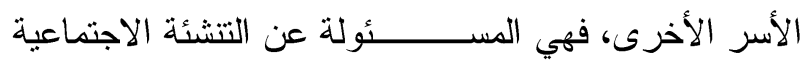

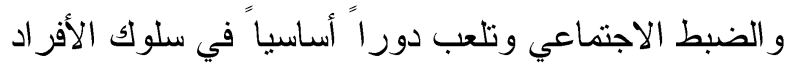
بطريقة سوية وغير سوية من خلال النماذج السلوكية التـي تقدما لأطفالها، فأنماط السلوك و التفاعلات التي تدور داخل دئل

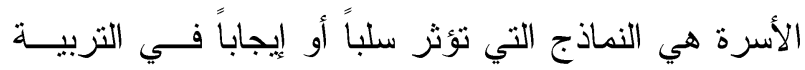
المرجعية للأطفال (صالح أبو جادو، V . . . ب). ولقد أوضح Blattner, M و آخرون(س ا • ץ) من خــلال الدر اسة التي أجريت بهدف در اسة العلاقة بـين اتجاهــات

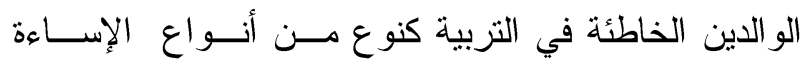

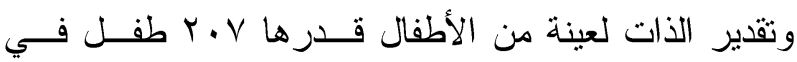

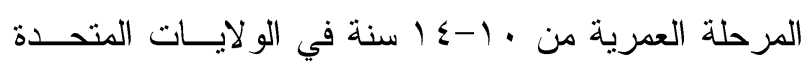

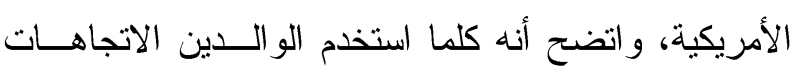
الخاطئة كلما انخفض مستوي تقدير الذات لدي الأبناء. 


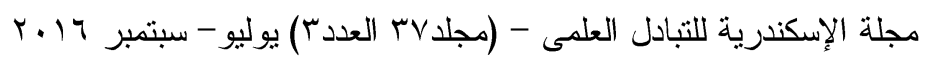

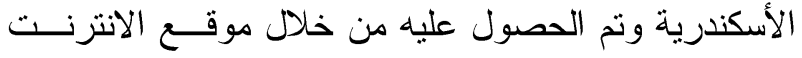

$$
\text { الخاص بوز ارة التزبية و التعليم(جدول ()). }
$$

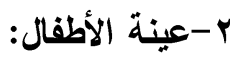

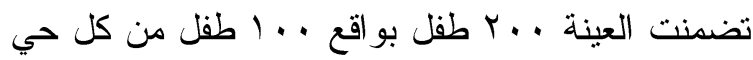

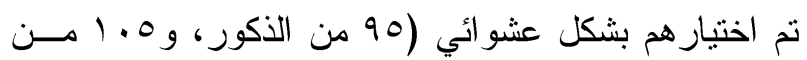
الإناث)، جميعهم في المرحلة العمرية من و-r ا سنة، في الصفوف الرابع و الخامس و السادس، منهم ع ب ا طفل مــن

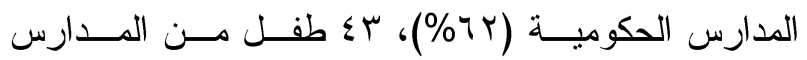

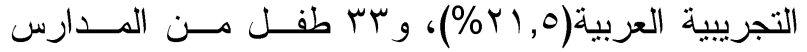

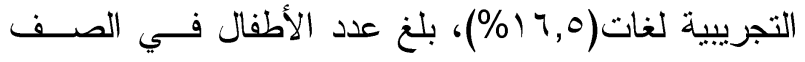

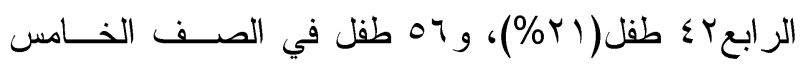

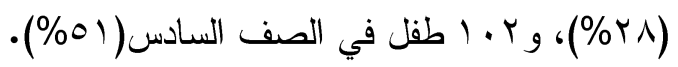
جدول ا. توزيع العينة البحثية تبعاً لنوع المدرسة

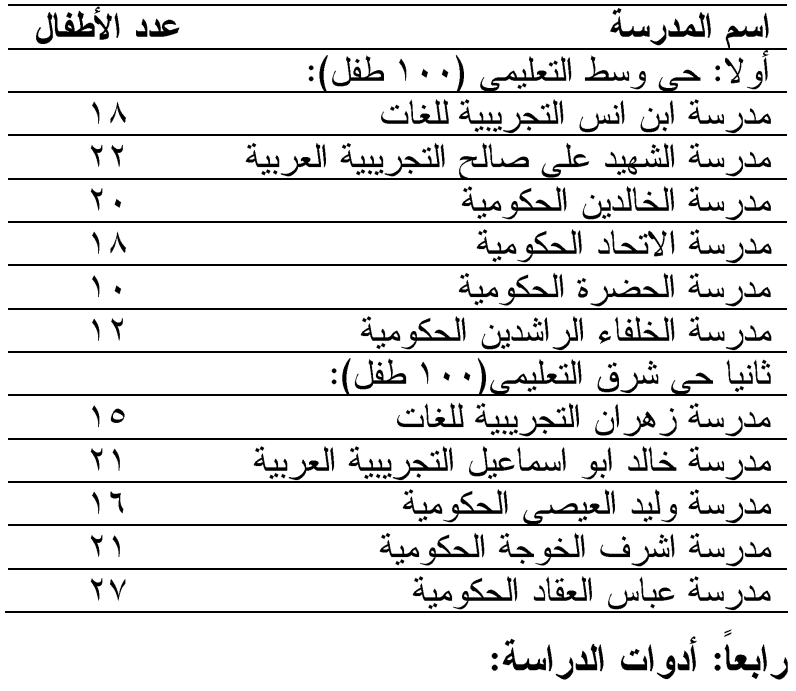

تحقيقاً لأهداف الدر اسة تم تصميم اســتمارتين اســتييان الأولي خاصة بأمهات الأطفال المبحوثين، و الثانية خاصـــة بالأطفال أنفسهم. أ- الاستمارة الخاصة بالأم: تتاولت بيانات عن الخصـــائص الشخصــية والأســرية للأطفال المبحوثين، تضمنت هذه البيانــات عمــر الطفــل، ولهـ

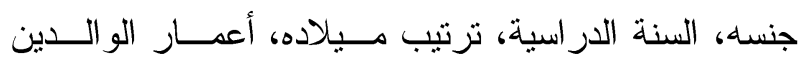

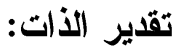

ويقصد بتقدير الذات في هذه الار اسة مجموعــة القــيم و الأفكار التي يمتلكها الطفل حول نفسه، وكيف يري نفسه، و يتضمن تقدير الطفل لذاته خمسة بنود: - تقدير الذات الجسمي و المقصود به أفكار الطفـلـل حــــل مظهره وشكله الخارجي وملابسه.

- تقدير الذات الاجتماعي و المقصود به أفكار الطفل حـول علاقته بالآخرين ومستوي نو اصله الإجتماعي معهم. - تقدير الذات المدرسي و المقصود به أفكار الطفل حــول مستو اه الدراسي وعلاقته بالمدرسة و المدرسين وكــذلك زملائه.

- الرضا عن الذات و المقصود به أفكار الطفل حول طبيعة شخصيته الداخلية. - الكفاءة الذاتية و المقصود بها أفكار الطفل حول ثته في تصر فاته و أفعاله. الإتجاهات الو الاية:

هي الأساليب التي يتبعها الآباء و الأمهات فـي تربيـــة وتتشئة أبنائهر وذللك من وجهة نظر الطفل، وتتضمن إتجاه

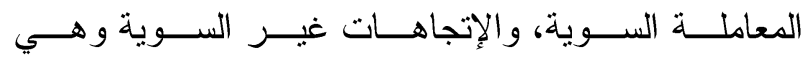

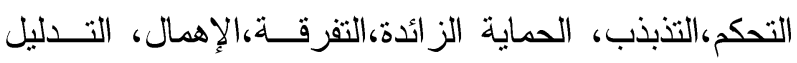
الز ائد، القسوة.

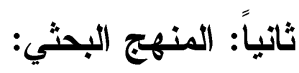
تستخدم الدراسة المنهج الوصفي التحليلي ثالثاً: العينة البحثية: ا - اعينة المدارس:

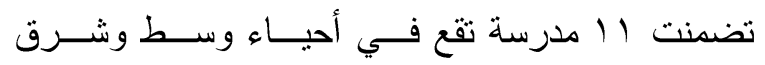
الأسكندرية بو اقع V مدارس حكومية، مدرستان تجريبيتـان حكوميتان، ومدرستان تجريبيتان للغات تم اختيار هم بطريقة عشوائية من خلال دليـلـل المــــارس الخــاص بمحافظـــة 
وقد بلغ الحد الأعلي للدرجات الرقمية إلي وس درجة، بينما بلغ الدد الأدني سا ا، وبذلك قسمت الدرجة الدالة علي الإساءة اللفظية و المعنوية إلي ب مستويات:

$$
\begin{aligned}
& \text { - مستوي منخفض: (Y| - ا (Y) درجة } \\
& \text { - مستوي متوسط: (ץ - - . } \\
& \text { - مستوي مرتفع: (اس - و (ץ) درجة } \\
& \text { المحور الثاني (تقدير الاتات): }
\end{aligned}
$$

وقد تضمن هذا المحور مجموعة من العبارات التي تقيد

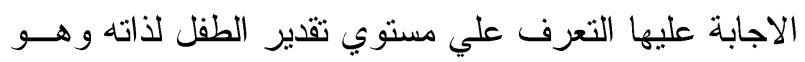

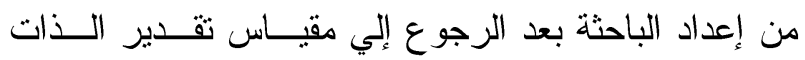

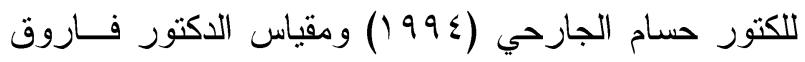
موسي والدكتور محمد دسوقي (999 (1)) ومقياس الــدكتورة

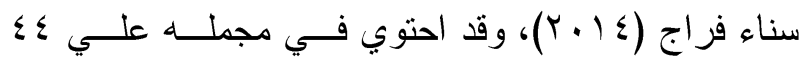
عبارة، كذلك تم وضع درجــات رقميــة (scores) لتقيــيم إجابات الأطفال المبحوثين بحيث أعطيت درجة و احدة فـي دي حالة عدم انطباق الجملة علي الطفل، وس درجات في حالة

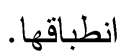

وقد تم تقسيم المقياس إلي ه أجزاء: 1- تقدير الأات الجسمي: تضمن مجمو عة من العبار ات تقيد الإجابة عليها التعرف علي مدي تقدير الطفل لمظهره الخارجي، وقد احتوي علي ع عبار ات، ولتقييم هذا التقدير تم وضع درجــات رقميــة

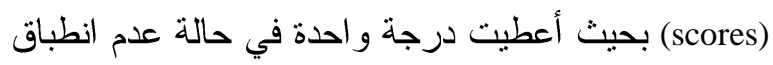
الجملة علي الطفل، وس درجات في حالة انطباقها. وقد بلغ الحد الأعلي للارجات الرقمية إلي با درجــة، بينما بلغ الحد الأدني ؛ درجات، قسمت الدرجة الدالة علي تقدير الذات الجسمي إلي ب مستويات:

$$
\begin{aligned}
& \text { - مستوي منخفض: (ع - ؟) درجة } \\
& \text { - مستوي متوسط: (V - } \\
& \text { - مستوي مرتفع: (· ( - Y I) درجة }
\end{aligned}
$$

ومستوي تعليمهما ووضعهما المهني، عدد أفراد الأســرة، عدد حجر ات المسكن و أخيراً درجة التزاحم الحجري. ب- إستمارة الطقل: ولقد تضمنت المحاور التالية: المحور الأول (الإساءة ضد الطقل): يشتمل علي أنماط الإسـاءة التي يتعرض لهــــا الطفــل، وذلك من خلال مقياس خبر ات الإساءة في مرحلة الطفولـــة

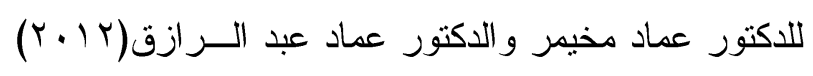
وذللك بعد تعديله وتقنينه، وقد نم تقسيم هذا المحــور إلــي قسمين، تضمن القسم الأول الإساءة الجسدية و القسم الثــاني تضمن الإساءة اللفظية و المعنوية. (القسم الأول: (الإساءة الجسدية)

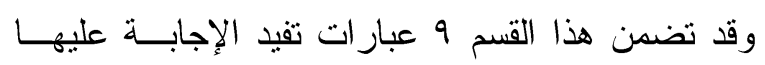
التعرف علي أنماط الإساءة الجسدية التي يتعرض لها الطفل و الأدوات المستخدمة في ذلك، وقد احتوي علي 9 عبار ات، ولتقييم ذلك تم وضع درجات رقمية(scores) بحيث أعطيت

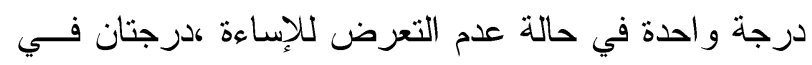
حالة أحياناً ورّ درجات في حالة التعرض الدائ. وقد بلغ الحد الأعلي للدرجات الرقمية rV درجة، بينما

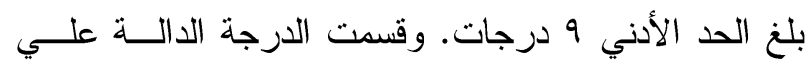
الإساءة الجسدية إلي س مستويات:

$$
\begin{aligned}
& \text { - مستوي منخفض: (9 - ک (1) درجة } \\
& \text { - مستوي منوسط: (10 - اYY) درجة } \\
& \text { - مستوي مرتفع: (Y - }
\end{aligned}
$$

القسم الثاني: (الإساءة اللفظية و المعنوية) وقد تضمن هذا القسم سا عبارة تفيد الاجابة عليها فـي التعرف علي أنماط الإساءة اللفظية و المعنوية التي يتعرض ولفي لها الطفل، ولتقييم ذلك تم وضع درجات رقميــة (scores) بحيث أعطيت درجة واحدة في حالة عدم التعرض للإساءة،

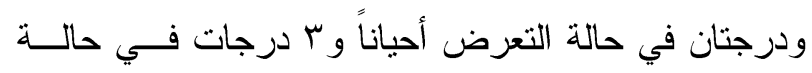
التعرض دائماً. 


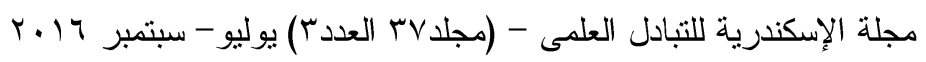

رقمية (scores)بحيث أعطيت درجة و احدة في حالة عـدم

انطباق الجملة علي الطفل، وس درجات في حالة انطباقها. وقد بلغ الحد الأعلي للارجات الرقمية إلي 1 درجــة،

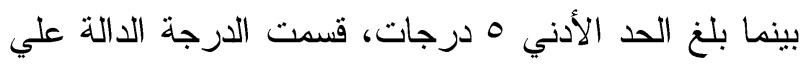
الرضا عن الذات إلي س مستويات: - مستوي منخفض: (0 - V ) درجة - مستوي متوسط: (1 - Y I) درجة - مستوي مرتفع: (با - - 0 (1) درجة

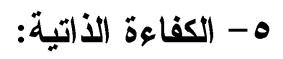
تضمن مجموعة من العبارات تفيد الإجابة عليها التعرف علي مدي ثقة الطفل في تصرفاته و أفعاله، وقد احتوي علي

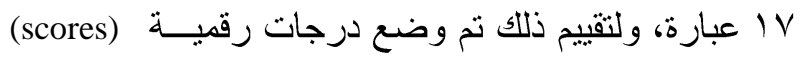
بحيث أعطيت درجة واحدة في حالة عدم انطبــاق الجملـــة علي الطفل، وس درجات في حالة انطباقها. وقد بلغ الحد الأعلي للدرجات الرقمية إلي اه درجة ، بينما بلغ الحد الأدني V IV درجة، قسمت الدرجة الدالة علي الكفاءة الذاتية إلي ب مستويات: - مستوي منخفض: (YV - IV) درجة

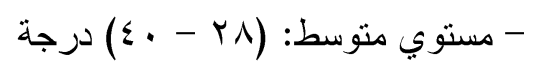
- مستوي مرتفع: (1) - - (0) درجة צ- تقدير الأات الكلي:

بلغ الحد الأعلي للارجات الرقمية الدالة علــي تقـدير

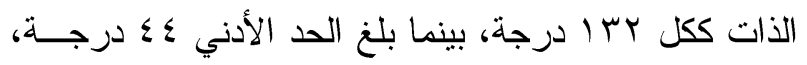
قسمت الدرجة الدالة علي تقدير الذات إلي ب مستويات:

$$
\begin{aligned}
& \text { - مستوي منخفض: (乏 ـ } \\
& \text { - مستوي متوسط: (VT - r • ()) درجة } \\
& \text { - مستوي مرتقع: (ع • 1 - rسו) درجة }
\end{aligned}
$$

r- تقدير الأت الاجتماعي:

تضمن مجموعة من العبارات تفيد الإجابة عليها التعرف علي مدي تقدير الطفل لعلاقته مع الآخرين، وقد احتــوي

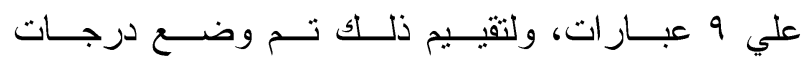
رقمية (scores) بحيث أعطيت درجة و احدة في حالة عـدم انطباق الجملة علي الطفل، وس درجات في حالة انطباقها. وقد بلغ الحد الأعلي للدرجات الرقمية rV درجة، بينما

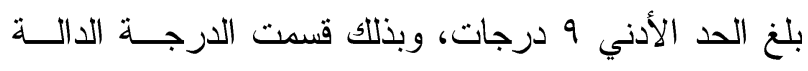
علي تقدير الذات الاجتماعي إلي ب مستويات:

$$
\begin{aligned}
& \text { - مستوي منخفض: (9 - § () درجة } \\
& \text { - مستوي متوسط: (10 - 1 (Y) درجة } \\
& \text { - مستوي مرتفع: (Y - - } \\
& \text { r- تقدير الأت المدرسي: }
\end{aligned}
$$

تضمن مجموعة من العبارات تفيد الإجابة عليها التعرف علي مدي تقدير الطفل لمستو اه الدراسي وعلاقته بالمدرسة

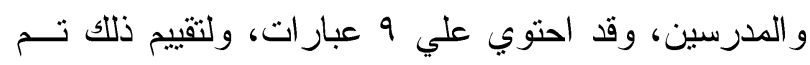

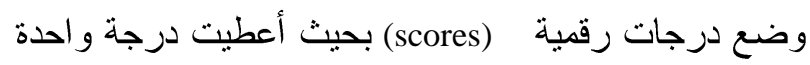
في حالة عدم انطباق الجملة علي الطفل، وب درجات فــي دلي حالة انطباقها. وقد بلغ الحد الأعلي للارجات الرقمية V درجة ، بينما بلغ الحد الأدني 9 درجات، قسمت الدرجة الدالة علي تقدير الذات المدرسي إلي ب مستويات:

$$
\begin{aligned}
& \text { - مستوي منخفض: (9 - § () درجة } \\
& \text { - مستوي متوسط: (10 - 1 (Y) درجة } \\
& \text { - مستوي مرتفع: (Y - Y - } \\
& \text { ع - الرضا عن الأت: }
\end{aligned}
$$

تضمن مجموعة من العبارات تفيد الإجابة عليها التعرف

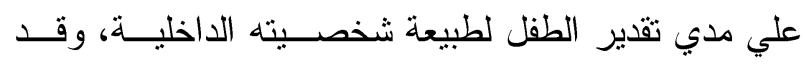

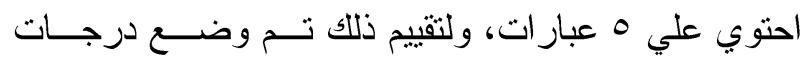


كما ير اها الطفل، وقد احتوي علي 9 عبارات، ولتقييم هذا الاتجاه تم وضع درجات رقمية (scores) بحيــث أعطيـــ

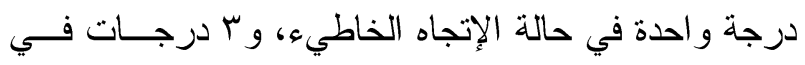
حالة الإتجاه الصحيح. وقد بلغ الحد الأعلي للارجات الرقمية rV درجة، بينما بلغ الحد الأدني 9 درجات، قسمت الدرجة الدالة علي اتجاه التحكم إلي س مستويات: - مستوي منخفض: (9 - ع () درجة - مستوي متوسط: (10 - (Y) درجة - مستوي مرتفع:(r) - r - درجة

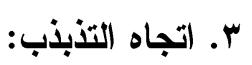
تضمن مجموعة من العبار ات تقيد الإجابة عليها التعرف

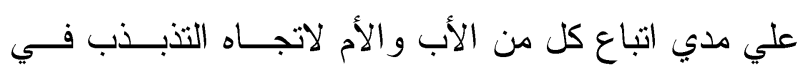

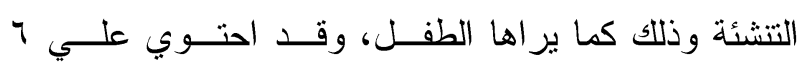

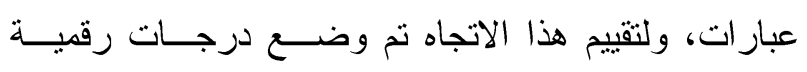

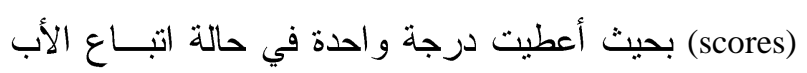

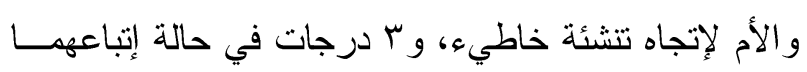
لإتجاه صحيح.

وقد بلغ الحد الأعلي للارجات الرقمية ه ا درجة، بينما بلغ الحد الأدني 7 درجات، قسمت الدرجة الدالة علي اتجاه التذبذب إلي ب مستويات:

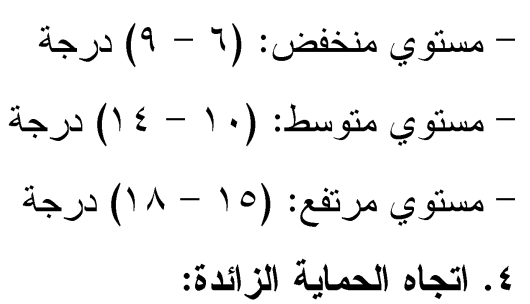
تضمن مجموعة من العبار ات تقيد الإجابة عليها التعرف علي مدي اتباع كل من الأب و الأم لاتجاه الحماية الزائـدة

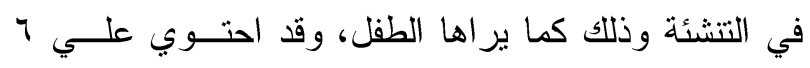

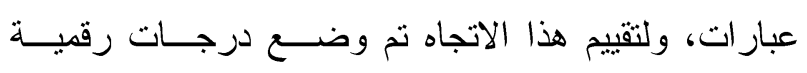

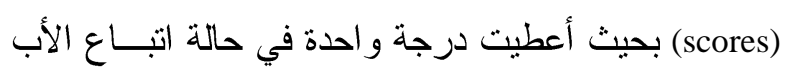

المحور الثالث (الاتجاهات الوالاية في التنشئة من وجهــة نظر الأبناء):

صورة المقياس: وقد تضمن بالج عبارة التي تفيد الاجابـة عليها في التعرف علي اتجاهات المعاملة الو الدية (صــورة الأب وصورة الأم) كما ير اها الطفل، وقد استعانت الباحثة بمقياس الدكتور محمد النوبي (؟ . . r) ومقياس الـدكتورة

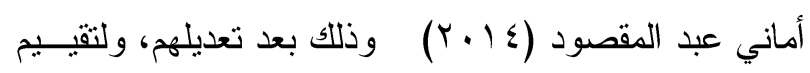

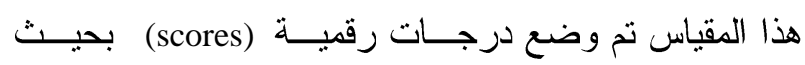

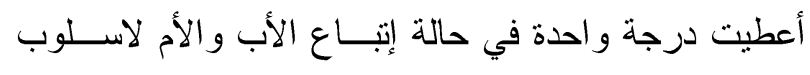

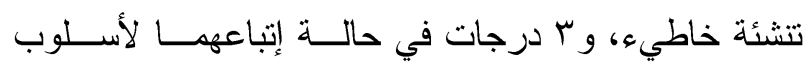
صحيح في التنشئة. وقد تم تقسيم الاتجاهات الو الدية إلي ^ اتجاهات هي: ا ـ اتجاه المعاملة السوية: تضمن مجموعة من العبارات تفيد الإجابة عليها التعرف علي مدي إتباع كل من الأب و الأم لاتجاه المعاملة الســوية

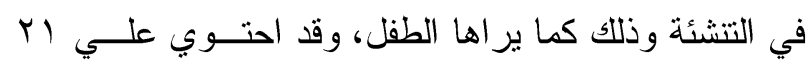
عبارة، ولتقييم هذا الاتجاه تم وضع درجات رقمية (scores) بحيث أعطيت درجة واحدة في حالة إتباع الأب و الأم لإتجاه

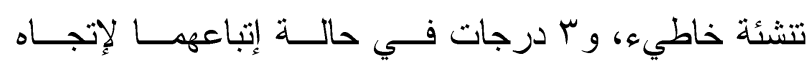

وقد بلغ الحد الأعلي للارجات الرقمية إلي با درجــة،

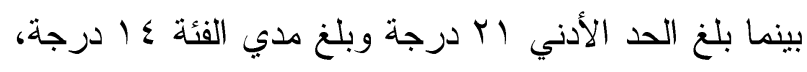
وبذلك قسمت الدرجة الدالة علي اتجاه المعاملة السوية إلي

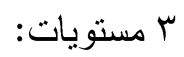

$$
\begin{aligned}
& \text { - مستوي منخفض: (اب - צ } \\
& \text { - مستوي متوسط: (0ب - و؟) درجة } \\
& \text { - مستوي مرتفع: ( (0 - سז) درجة }
\end{aligned}
$$

تضمن مجموعة من العبارات تفيد الإجابة عليها التعرف علي مدي اتباع كل من الأب والأم لاتجاه التحكم في التنشئة 


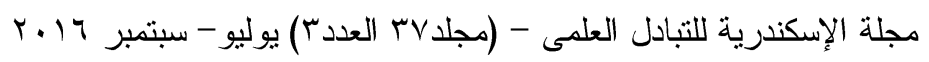

درجات ثقريبا، وبذلك قسمت الدرجة الدالــة علــي اتجــاه

$$
\text { الإهمال إلي ب مستويات: }
$$$$
\text { - مستوي منخفض: (0 - V ( ) درجة }
$$$$
\text { - مستوي متوسط: (1 - r I) درجة }
$$$$
\text { - مستوي مرتفع: (سו - } 0 \text { (1) درجة }
$$

V. اتجاه التدليل الزائد:

تضمن مجموعة من العبار ات تفيد الإجابة عليها التعرف علي مدي إتباع كل من الأب و الأم لاتجاه التدليل الزائد في

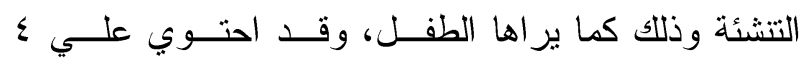
عبار ات، ولتقييم هذا الاتجاه تم وضـــع درجــات رقميــة بحيث أعطيت درجة واحدة في حالة اتبــاع الأب (scores)

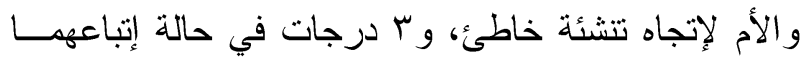

لإتجاه صحيح.

وقد بلغ الحد الأعلي للارجات الرقمية إلي با درجـة، بينما بلغ الحد الأدني ؛ درجات، قسمت الدرجة الدالة علي الدي اتجاه التدليل الزائد إلي ب مستويات: - مستوي منخفض: (ع - 7) درجة - مستوي متوسط: ( - -

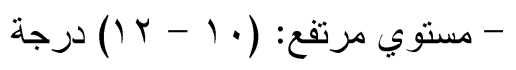

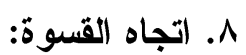

تضمن مجموعة من العبار ات تقيد الإجابة عليها التعرف علي مدي إتباع كل من الأب والأم لاتجاه القسوة في التنشئة وذللك كما ير اها الطفل، وقد احتوي علي ؛ عبار ات، ولتقييم هذا الاتجاه تم وضع درجات رقمية (scores) بحيث أعطيت

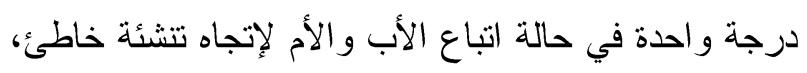
وس درجات في حالة إتباعهما لإتجاه صحيح. وقد بلغ الحد الأعلي للارجات الرقمية إلي با درجــة،

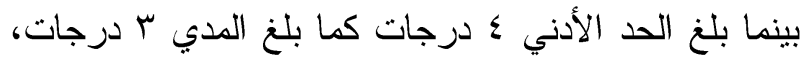

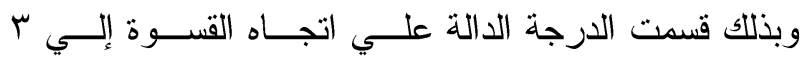

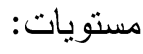

و الأم لإتجاه تتشئة خاطيء، وس درجات في حالة إتباعهــــا لإتجاه صحيح. وقد بلغ الحد الأعلي للارجات الرقمية إلي ه ا درجــة، بينما بلغ الحد الأدني 7 درجات، قسمت الدرجة الدالة علي الدي اتجاه الحماية الز ائدة إلي ب مستويات: - مستوي منخفض: (7 - 9) درجة - مستوي منوسط: (• (1 - ع 1) درجة - مستوي مرتفع: (10 - 1 1) درجة

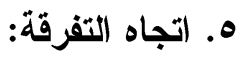

ولقياس هذا الغتجاه تم وضع V عبار ات تقيــد الإجابــة

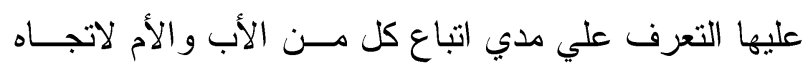
التقرقة في التنشئة كما ير اها الطفل، ولتقييم هذا الاتجاه تــم

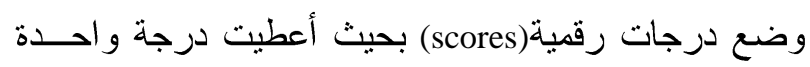

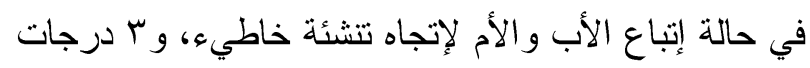
في حالة إتباعهما لإتجاه صحيح.

وقد بلغ الحد الأعلي للارجات الرقمية اY درجة، بينما بلغ الحد الأدني V درجات ، قسمت الدرجة الدالة علي اتجاه التفرقة إلي ب مستويات:

$$
\text { - مستوي منخفض: (V - l ( ) درجة }
$$
- مستوي متوسط: (Y ( - ד 1) درجة - مستوي مرتفع: (Y - (Y) درجة

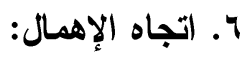
تم وضع م عبار ات تفبد الإجابة عليها التعـرف علـي مدي اتباع كل من الأب و الأم لاتجاه الإهمال فــي التتشـئة

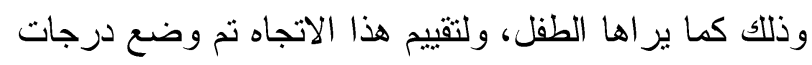

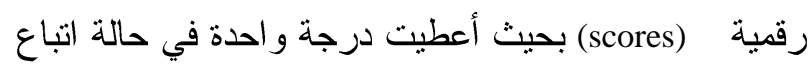

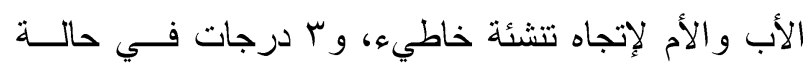

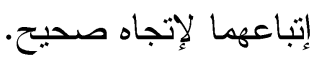
وقد بلغ الحد الأعلي للارجات الرقمية إلي 10 درجــة،

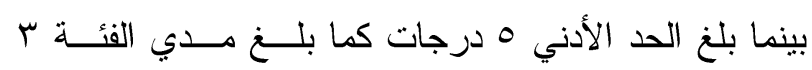




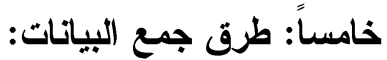

تم جمع البيانات بالمقابلة الثخصية مع الأطفال داخـلـل

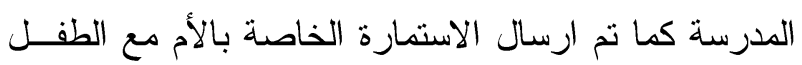
وذللك لجمع البيانات الثخصية و الأسرية الخاصة بالطفل. سادساً: التحليل الإحصائي:

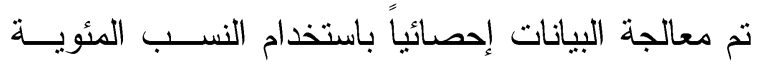
و المتوسط الحسابي و الانحر اف المعياري كـدليل لإظهــار

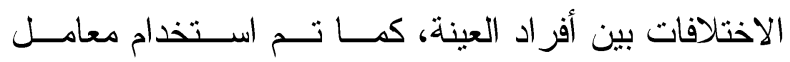
الارتباط بيرسون Person's Correlation Coefficient وذلك لاختبار قوة العلاقة بين بعض المتغير ات المستقلة و التابعــة

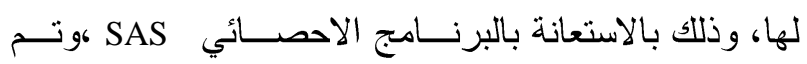

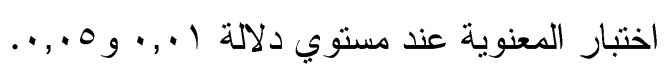

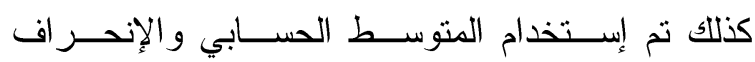
المعياري وإختبار ألفا كرونباخ.

\section{النتائج البحثية}

أولاً: النتائج المتعلقة بالخصائص الثخصـية والأســرية للأطفال: - الا:

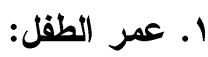

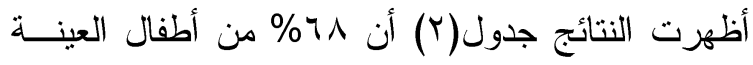

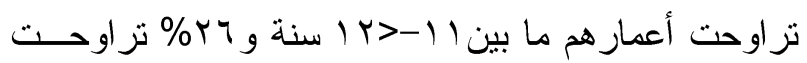

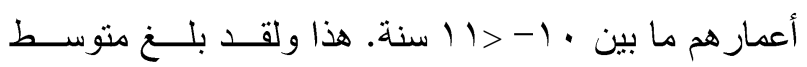
أعمار الأطفال المبحوثين 11.13ـ0.66.

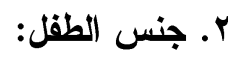

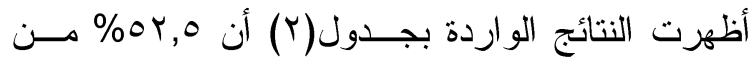

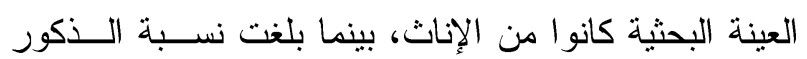
$\% \leqslant \vee, 0$

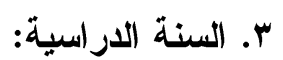
أظهرت النتائج ان 10 1\% من الأطفال المبحوثين كــانوا من الملتحقين بالصف السادس الإبتدائي، الإن

$$
\begin{aligned}
& \text { - مستوي منخفض: (؟ - ؟) درجة } \\
& \text { - مستوي متوسط: ( v - (9) درجة }
\end{aligned}
$$

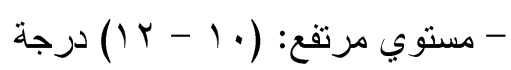

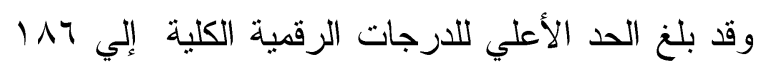

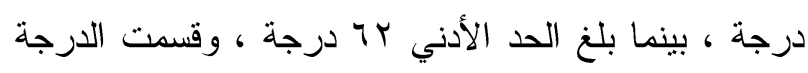
الدالة علي اتجاهات المعاملة الو الدية إلي بـ مستويات:

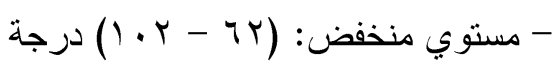

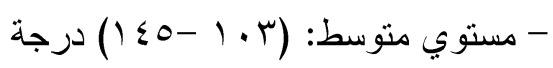

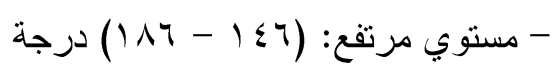

حساب صدق المقاييس:

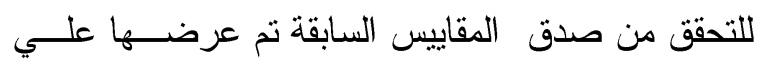

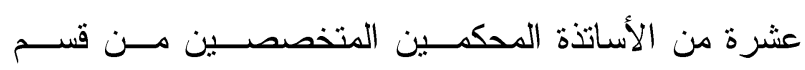

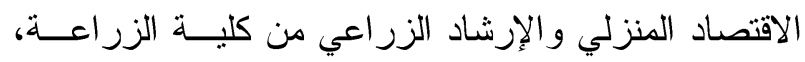

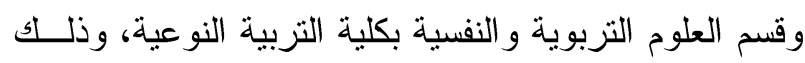
للتعرف علي آرائهم فيه من حيث مدي مناسبة كل عبـارة للجانب الذي تقيمه ومدي صحة صياغة العبارات. وقد نم حساب نكرارات الإتفاق بين المحكمين علي كل

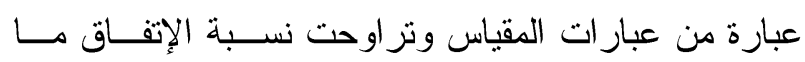
بين .9 - ... 1 \% لمقياس الإساءة للطفل ومقيــاس تقدير

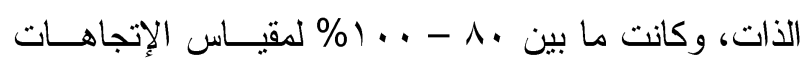

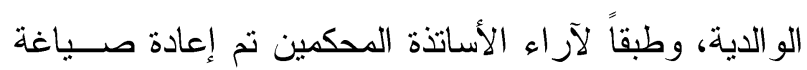
بعض العبارات فيه وتم إعداده للصورة النهائية.

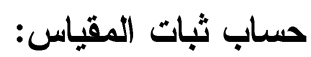

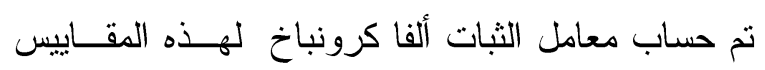

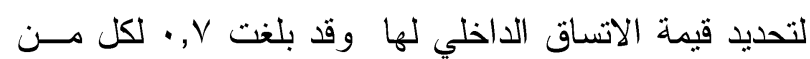

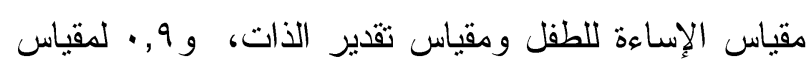

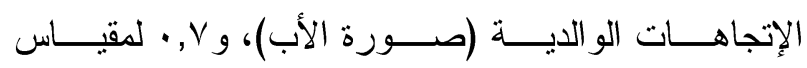
الإتاجاهات الو الدية (صورة الأم). 


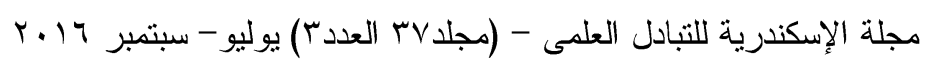

جدول r. توزيع العينة البحثية تبعاً للخصائص الثخصية والأسرية للعينة البحثية

\begin{tabular}{|c|c|c|c|c|}
\hline \multirow{2}{*}{\multicolumn{2}{|c|}{ 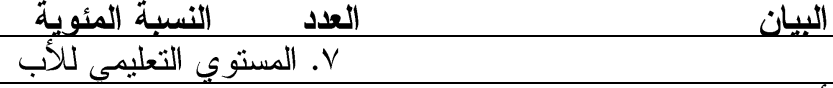 }} & النسبة & 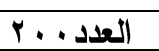 & البيان \\
\hline & & & & ا ا.عمر الطفل بالسنة \\
\hline$\varepsilon, \ldots$ & أمى & $7, \ldots$ & Ir & $1 .>-9$ \\
\hline $11, \ldots$ & 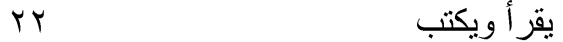 & $r q, \ldots$ & or & $11>-1$. \\
\hline$I \Gamma \ldots$ & شيهادة انتدائية & $7 \Lambda_{1} \ldots$ & 149 & $|r-1|$ \\
\hline 11,0 . & شهادة اعدادية & \multicolumn{3}{|c|}{ المتوسط الحسابيـ الانحر اف المعياري0.66_11.13 } \\
\hline$r \leqslant, 0$. & شهادة ثانوية أو ما يعادلها & \multicolumn{3}{|c|}{ r.ب.جنس الطفل } \\
\hline$r \varepsilon, \ldots$ & مؤهل جامعي & $\varepsilon \vee, 0$. & 90 & ذكر \\
\hline$r, \cdots$ & 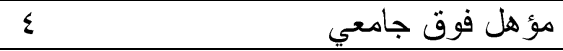 & \multicolumn{3}{|l|}{ or,o. } \\
\hline 1.مهنة الأب & & \multicolumn{3}{|r|}{ 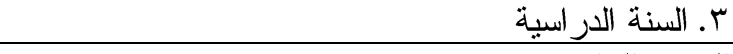 } \\
\hline$r \cdot, \cdot$. & أعمال مهنية & \multirow{2}{*}{\multicolumn{3}{|c|}{ الصف الخفامس }} \\
\hline$r 4,0$. & أعمال إدارية & & & \\
\hline or,o. & أعمال حر فية & \multirow{2}{*}{\multicolumn{2}{|c|}{$01, \ldots \quad 1 . r$}} & \multirow{2}{*}{ ع. الصف ع السدرسة } \\
\hline 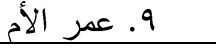 & & & & \\
\hline $\mathrm{v}, \mathrm{O}$. & 10 & $T r, \ldots$ & Ir & حكومي \\
\hline $1 \wedge, \cdots$ & 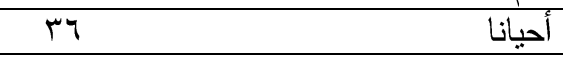 & ri,o. & $\varepsilon r$ & تجريبى عربى \\
\hline$V \varepsilon, 0$. & $1 \leq 9$ & $17,0$. & זr & تجريبي لغات \\
\hline \multicolumn{2}{|c|}{ المتوسط الحسابي土 الانحر اف المعياري5.26 38.58 } & \multicolumn{3}{|r|}{ 0. ترتيب الميلاد } \\
\hline \multicolumn{2}{|c|}{ 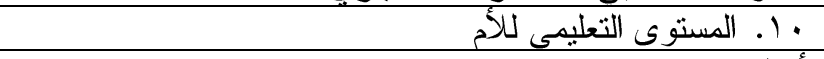 } & $r_{0, \ldots}$ & $\mathrm{v} \cdot$ & الأول \\
\hline$v, \ldots$ & أمية & $r r, 0$. & IV & \multirow{2}{*}{ الثالثى } \\
\hline $9, \ldots$ & تقر أ وتكتب & \multirow{2}{*}{$\frac{19, \ldots}{\gamma, 0 .}$} & ru & \\
\hline $0, \ldots$ & شهادة إبتدائية & & 10 & 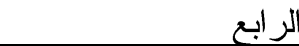 \\
\hline$i r, \ldots$ & شهادة إعدادية & r,o. & 0 & 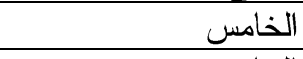 \\
\hline$\varepsilon \varepsilon, \ldots$ & شهادة ثانوبة أو مابعادلها & \multirow[t]{2}{*}{ r,o. } & 0 & \multirow{2}{*}{ آ.عمر الأب } \\
\hline $1 \Lambda, 0$. & تحمل مؤهل جامعى. & & & \\
\hline \multirow[t]{2}{*}{$r, 0$. } & تحمل مؤهل فوق جامعىى & \multirow{2}{*}{$\begin{array}{l}1 \%, 0 . \\
0 \wedge .0 .\end{array}$} & tr & $\varepsilon \cdot>$ \\
\hline & 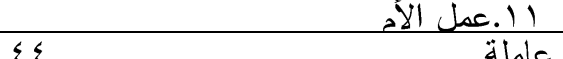 & & $11 \mathrm{~V}$ & $0 .>-\varepsilon$. \\
\hline \multirow{2}{*}{$\vee \wedge, \ldots$} & غاملة عاملة & $\frac{0 \lambda, 0,}{r V, \ldots}$ & $\frac{0 \xi}{r}$ & $\begin{array}{ll}4 .>-0 . \\
4.5 \%\end{array}$ \\
\hline & & \multicolumn{3}{|c|}{ المتوسط الحسابي الانحر اف المعياري5.77_45.32 } \\
\hline \multicolumn{2}{|c|}{ با..درجة التز احم الحجري } & \multicolumn{3}{|c|}{ r Y. (عدد أفر اد الأسرة } \\
\hline$V 7,0$ & | بر Y فرد| حجرة & $\varepsilon, 0$ & 9 & $r-r$ \\
\hline$r \mu, 0$. & | > > برد / حجرة & $70, \ldots$ & $1 \pi$. & $0-\varepsilon$ \\
\hline & & $r \cdot, 0$. & 71 & ד فأكثز \\
\hline
\end{tabular}

الملتحقين بالمــارس التجرييــة(عربي)، و 17,0 \% مــن

$$
\text { ه. ترتيب الميلاد: }
$$

بلغت نسبة الأطفال المبحوثين ممن كان تــرتيهم الأول

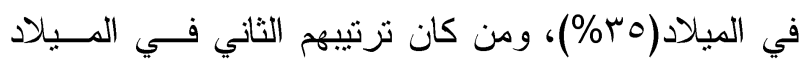

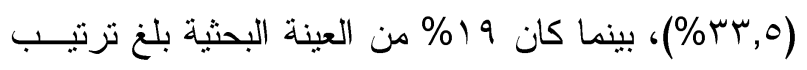

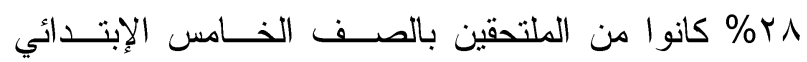

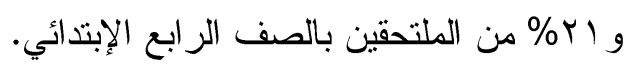

ع. نوع المدرسة:

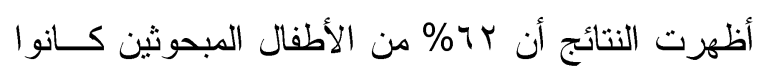

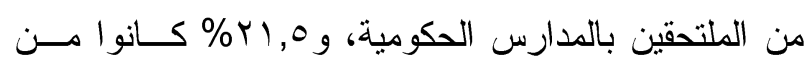


أفر اد أسرهم ع-0 فرد 70\% يلي ذلك 0, • ب\% بلغ عـدد

$$
\text { أفر اد أسر هم } 7 \text { فرد فأكثر. }
$$

• أ درجة التزاحم الحجري:

بلغت درجة التزاحم الحجري لأسر الأطفال المبحـــثين

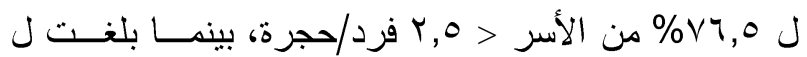

r,

ثانياً: النتائج المتعلقة بمستوي الإساءة التي يتعرض لهـا

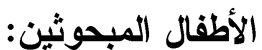

يشير جدول(r) وشكل(r، (1) إلي كل من مستوي شــدة

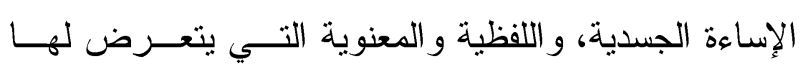

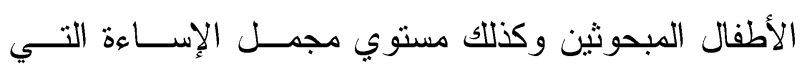

$$
\text { يتعرضون لها. }
$$

ولقد أظهرت النتائج أن بـ أنفلاً من إجمالي العينــة البحثية تعرضوا للإسـاءة الجسدية (\%/\%) مــابين شـديدة

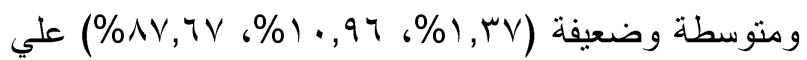

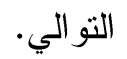

اتفقت هذه النتيجة مع ما وجده Ramadan,S و آخــرون

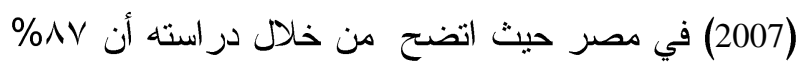
من أطفال العينة قد تعرضوا للإساءة الجسدية، بينما اختلفت ملت هل مع ما وجده .Duncan, A و آخرون (2015) فــي الولايــات

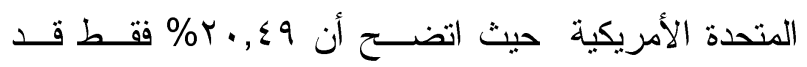

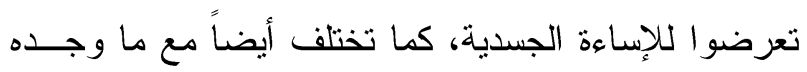
Rossa, A.

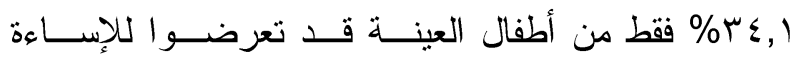

الجسدية.

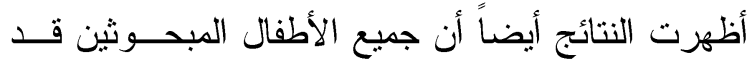
تعرضو اللإسـاءة اللفظية و المعنوية ما بين درجات شـديدة

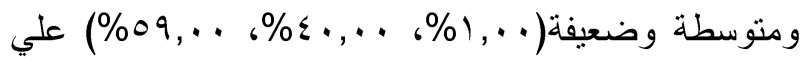

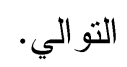

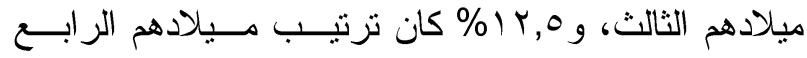
فأكثر.

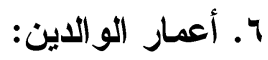

بلغت نسبة الآباء الذين تراوحت أعمارهم ما بين • ــ -

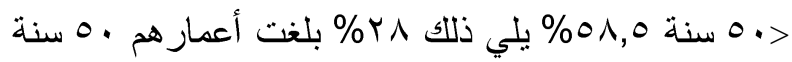

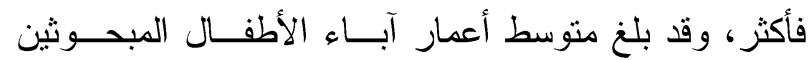
$.45 .32 \pm 5.77$

كذلك أظهرت النتائج أن 0,0\%\% من أمهات الأطفــال

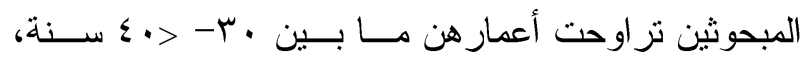

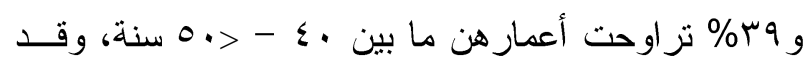
بلغ متوسط أعمار أمهات الأطفال المبحوثين 5.26 38.58. V . المستوي التعليمي للوالدين:

بلغت نسبة الحاصلين علي مؤهل جامعي فــأكثر بr\%

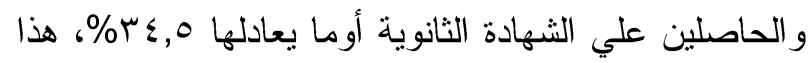

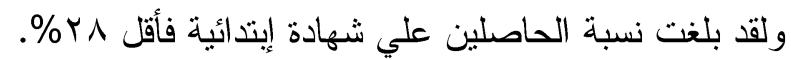
كذلك أظهرت النتائج أن نسبة الأمهات الحاصلات علي تعليم جامعي فأكثر rr\%، ومن يحملن الثهادة الثانوية أوما

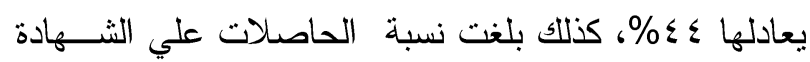

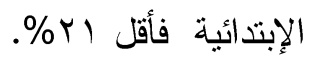

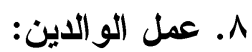

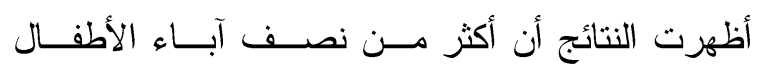
المبحوثين كانوا من العاملين بأعمال حرفية (0, به\%)، يلي

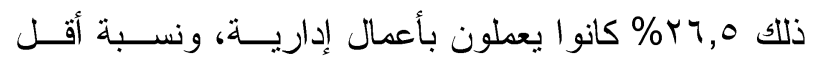

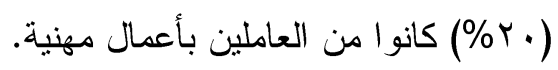
أظهرت النتائج أيضاً أن ما يقرب من 3/4 عينة الأمهات

$$
\text { كن غير عاملات. }
$$

9

بلغ متوسط عدد أفر اد الأسرة بين أطفال العينة البحثيــة

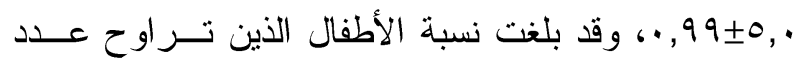


جدول r. توزيع العينة البحثية تبعاً لثدة الإساءة

\begin{tabular}{|c|c|c|}
\hline النسبة المئويةً & 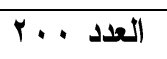 & مستوي شدة الإساءة \\
\hline & & الإسـاءة الجسدية \\
\hline$r V, \ldots$ & $0 \varepsilon$ & غير متعرضين \\
\hline$T \varepsilon, \ldots$ & IYA & إساءة ضعيفة( · - ـ () درجة \\
\hline A... & 17 & إساءة متوسطة (1T - 17 - درجة \\
\hline \multirow[t]{2}{*}{$1, \ldots$} & $r$ & إسباءة شديدة (YY - Y (YV) درجة \\
\hline & & الإساءة المعنوية و اللفظية \\
\hline- & - & غير هتعرضين \\
\hline $1, \ldots$ & r & إساءة شديدة (1 - - (T) درجة \\
\hline$\varepsilon \cdot, \ldots$ & A. & إساءة متو سطة (Y - - · ·r) درجة \\
\hline \multirow[t]{2}{*}{$09, \ldots$} & 111 & إساءة ضعيفة (T) - (Y) درجة \\
\hline & & مجمل الإساءة التى يتعرض لها الأطفال \\
\hline $1, \ldots$ & $r$ & إساءة شديدة (Tr-OT) درجة \\
\hline 10,0 & ri & إساءة متو سطة ( ب - T T) درجة \\
\hline$\Lambda \uparrow, 0$. & $17 \mathrm{~V}$ & 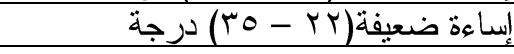 \\
\hline- & - & غير متعرضين \\
\hline
\end{tabular}

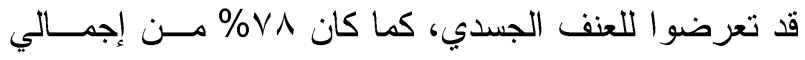
الأطفال ضحايا للعنف النفسي.

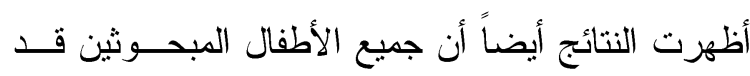

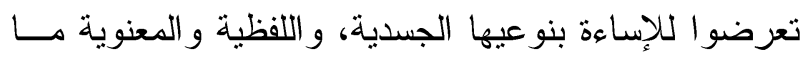

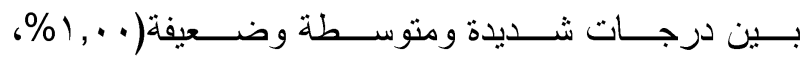
.

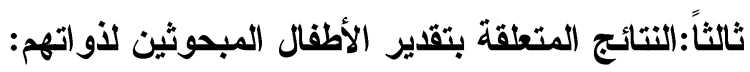

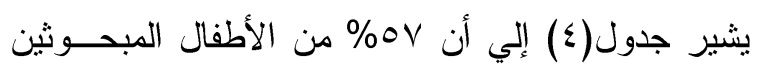

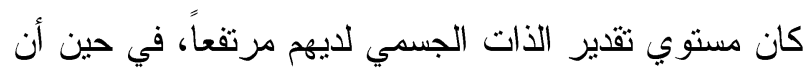

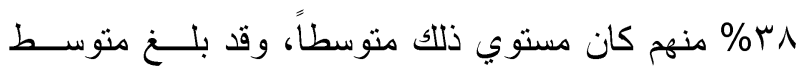

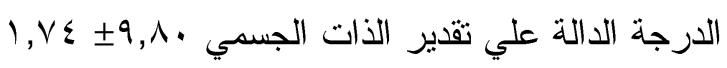

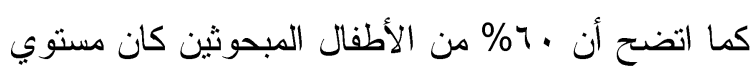
تقدير الذات الاجتماعي لديهم مرتفعاً، في حين كان منوسطاً

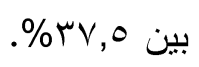

وقد بلغ منوسط الدرجة الدالـــة علــي تقــير الـــات الإجنماعي
ومن ذللك يتضح أن نمط الإساءة الأكثر شـيوعاً بــين أطفال العينة البحثية هو الإساءة اللفظية و المعنوية.

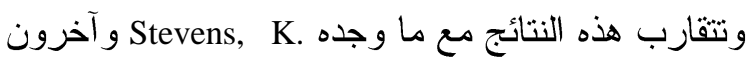

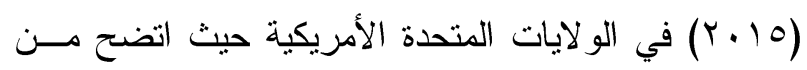

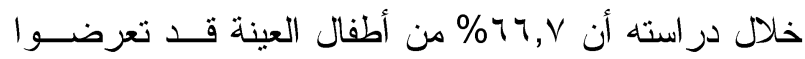

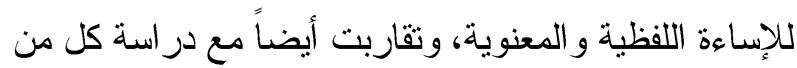
Gooding, H.

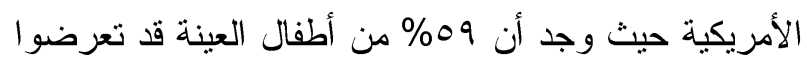

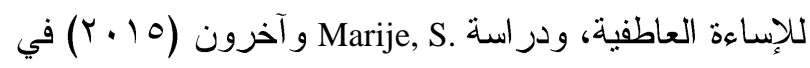
هولندا حيث وجد أن ب, ؟ب\%\% من أطفال العينة قد تعرضوا

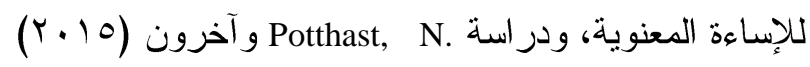

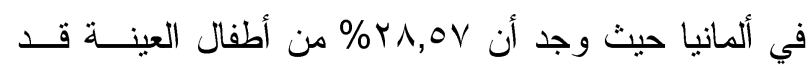
تعرضو اللإساءة المعنوية. ومن خلال الدراسة التي أجر اها المجلس القومي للطفولة

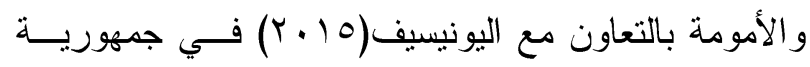

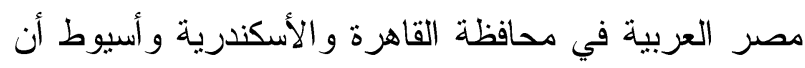

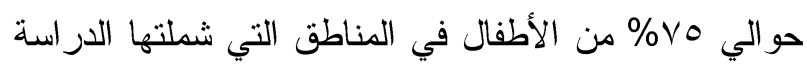




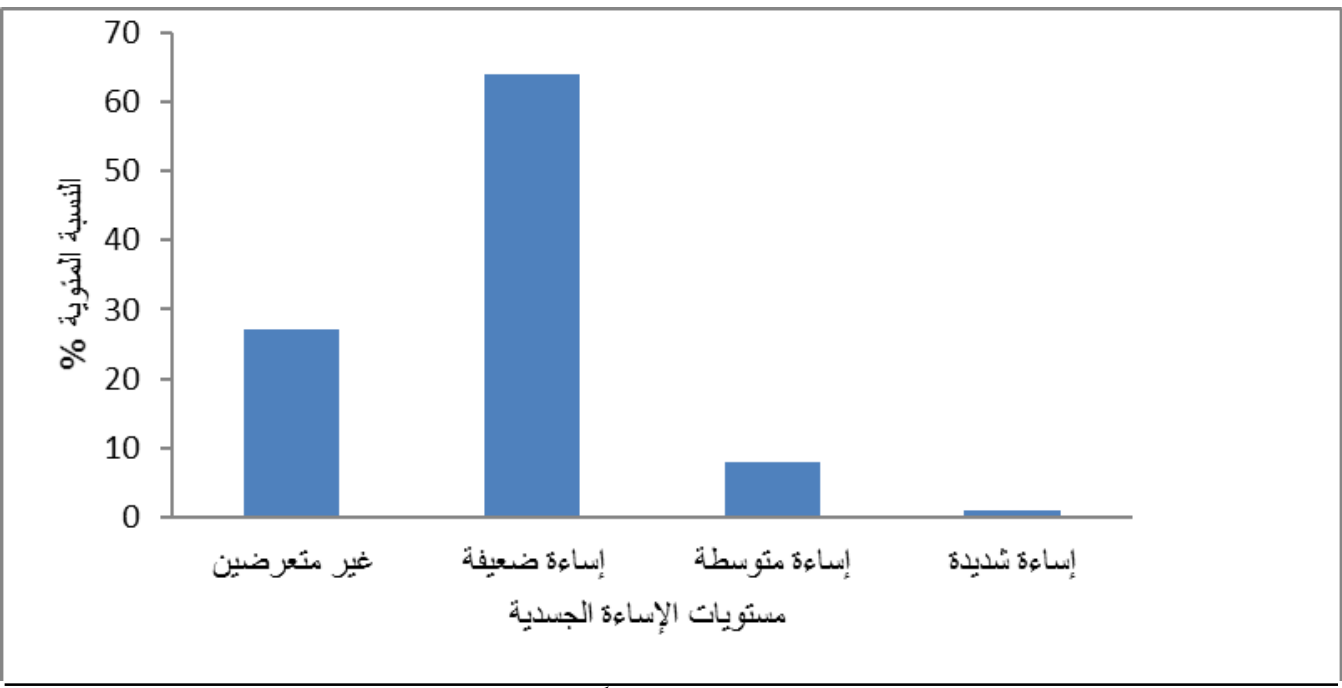

شكل ا ـ توزيع العينة البحثية تبعاً لثدة الإساءة الجسدية

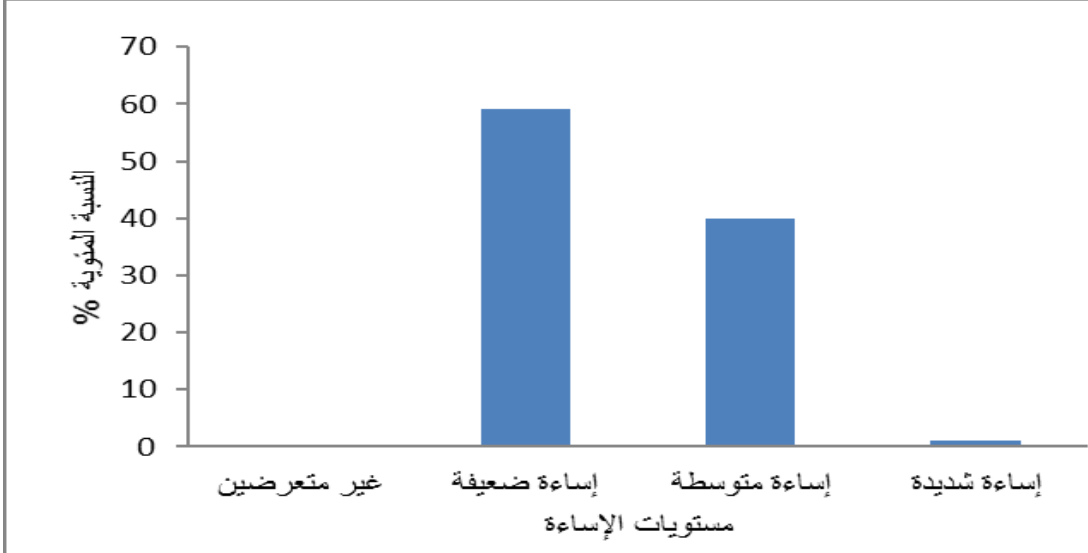

شكل r ـ توزيع العينة البحثية تبعاً لثدة الإساعة المعنوية واللفظية

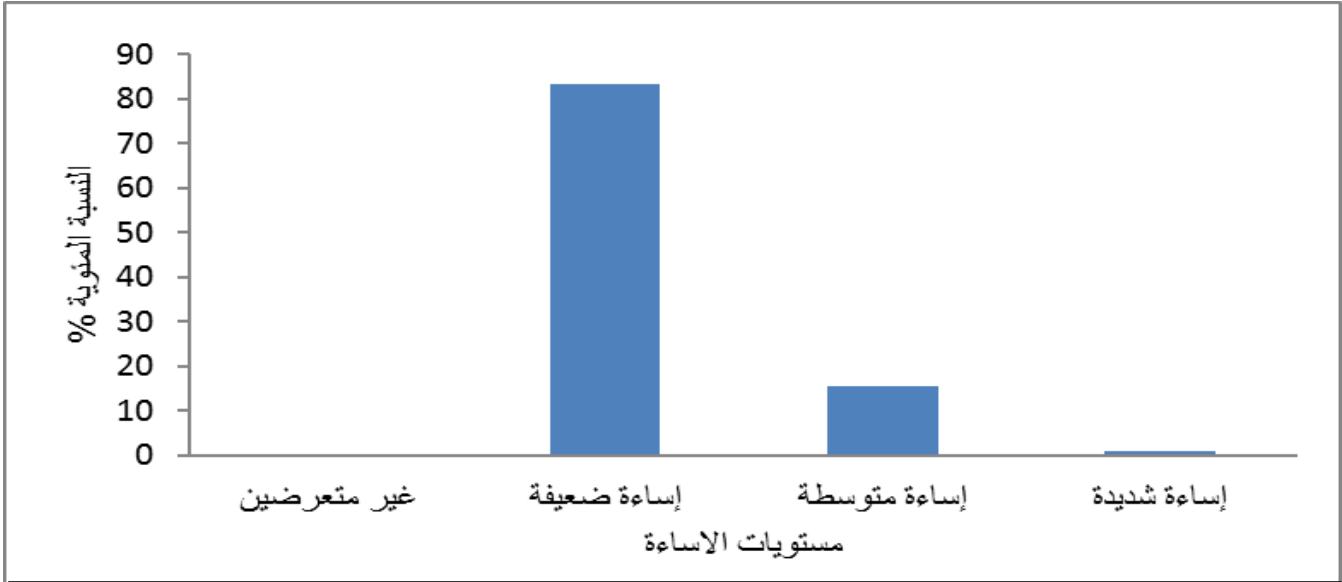

شكل r. توزيع العينة البحثية تبعاً مجمل الإساءة التى يتعرض لها الأطفال 
جدول ع. توزيع العينة البحثية تبعاً لمستويات تقدير الأات

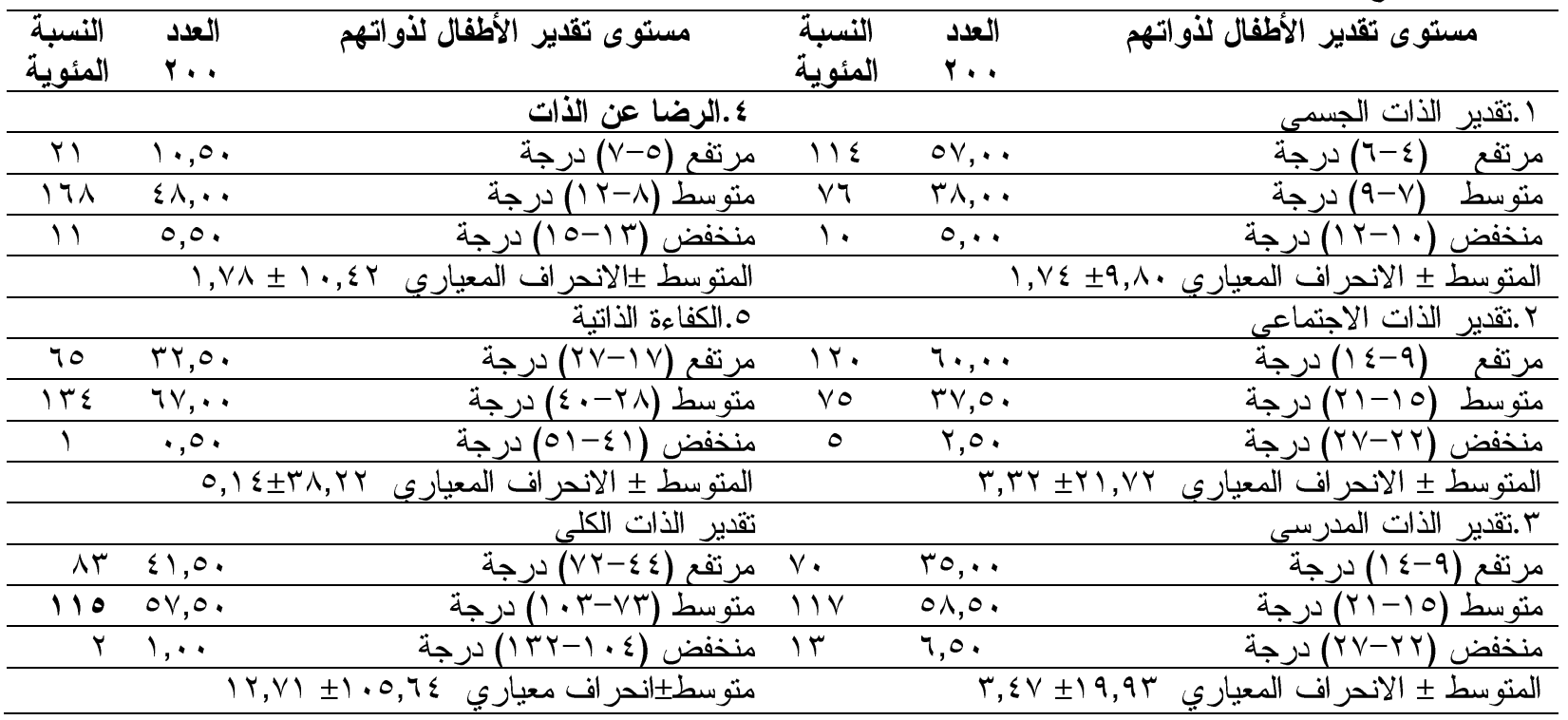

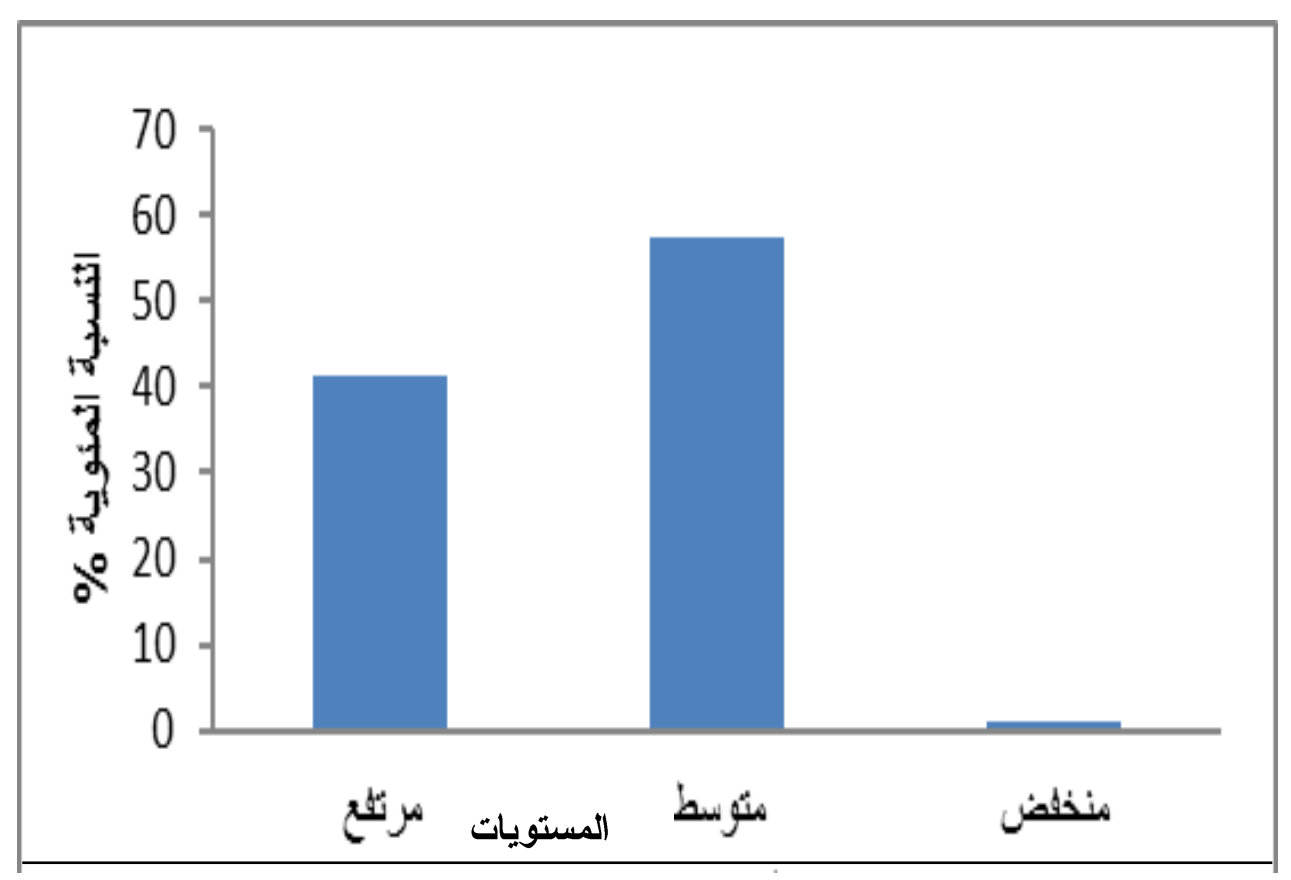

شكل ؛. توزيع العينة البحثية تبعاً لمستويات تقدير الذات

كذلك اتضح مـن البيانـات أن ع^م\% مـن الأطفــال المبحوثين كان مستوي الرضا عن ذو اتهم متوسطاً. وقد بلغ الغان

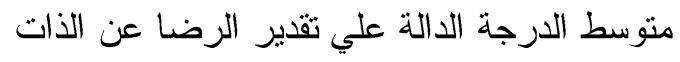

$$
.1, \vee \wedge \pm 1 \cdot, \varepsilon r
$$

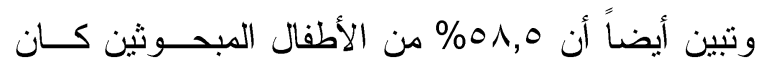

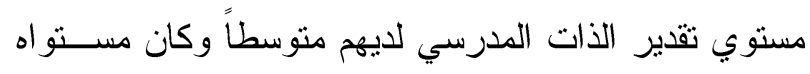

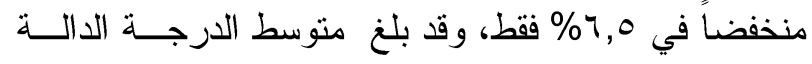

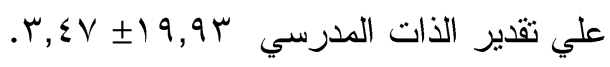




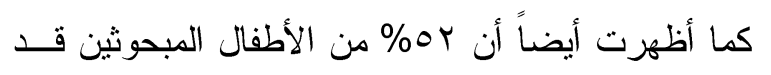
حصلو ا علي درجات منوسطة في مجمل الاتجاهات الو الدية

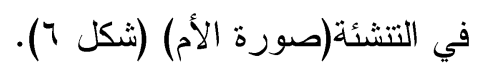

خامساً: العلاقات الإرتباطية:

1. العلاقات الإرتباطية بين بعض الخصــائص الشخصـية

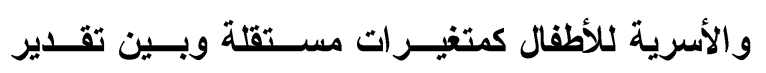
الأطفال لذواتهم كمتغير تابع:

أ- العلاقة الإرتباطية بين الخصائص الشخصية والأســرية

$$
\text { وتقدير الأات الجسمي: }
$$

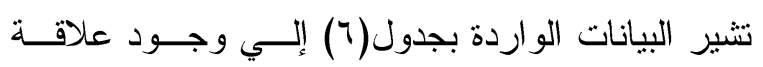

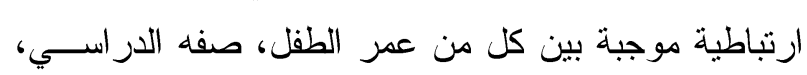
ترتيب ميلاده، مهنة الأب، المستوي التعليمي للأم وعملها، وعدد أفر اد الأسرة كمتغيرات مستقلة وتقدير الذات الجسمي
وتبين أن VT\% من الأطفال المبحوثين كــان مســتوي

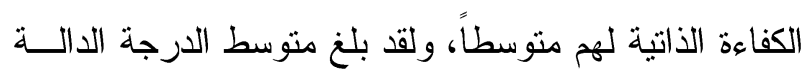

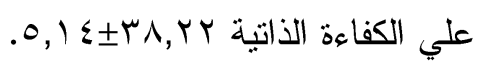
أما عن مستوي تقدير الذات الكلي أظهرت النتــائج أن \% من \% o

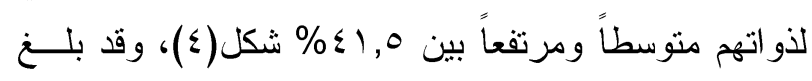

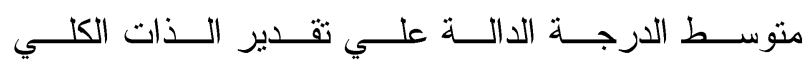
$.1 Y, V \pm 1 \cdot 0,7 \varepsilon$ رابعاً: النتائج المتعلقة بالإتجاهات الوالدية في التشئة من وجهة نظر الأطفال:

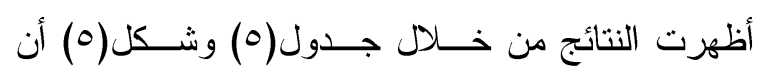
T ب, •0\% من الأطفال المبحوثين قد حصلو ا علي درجـات متوسطة في مجمل الاتجاهات الوالدية في التنشئة(صــورة

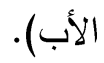

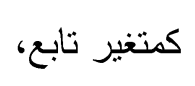

جدولهـ توزيع العينة البحثية تبعاً للإتجاهات الوالاية في التثشئة من وجهة نظر الأطفال

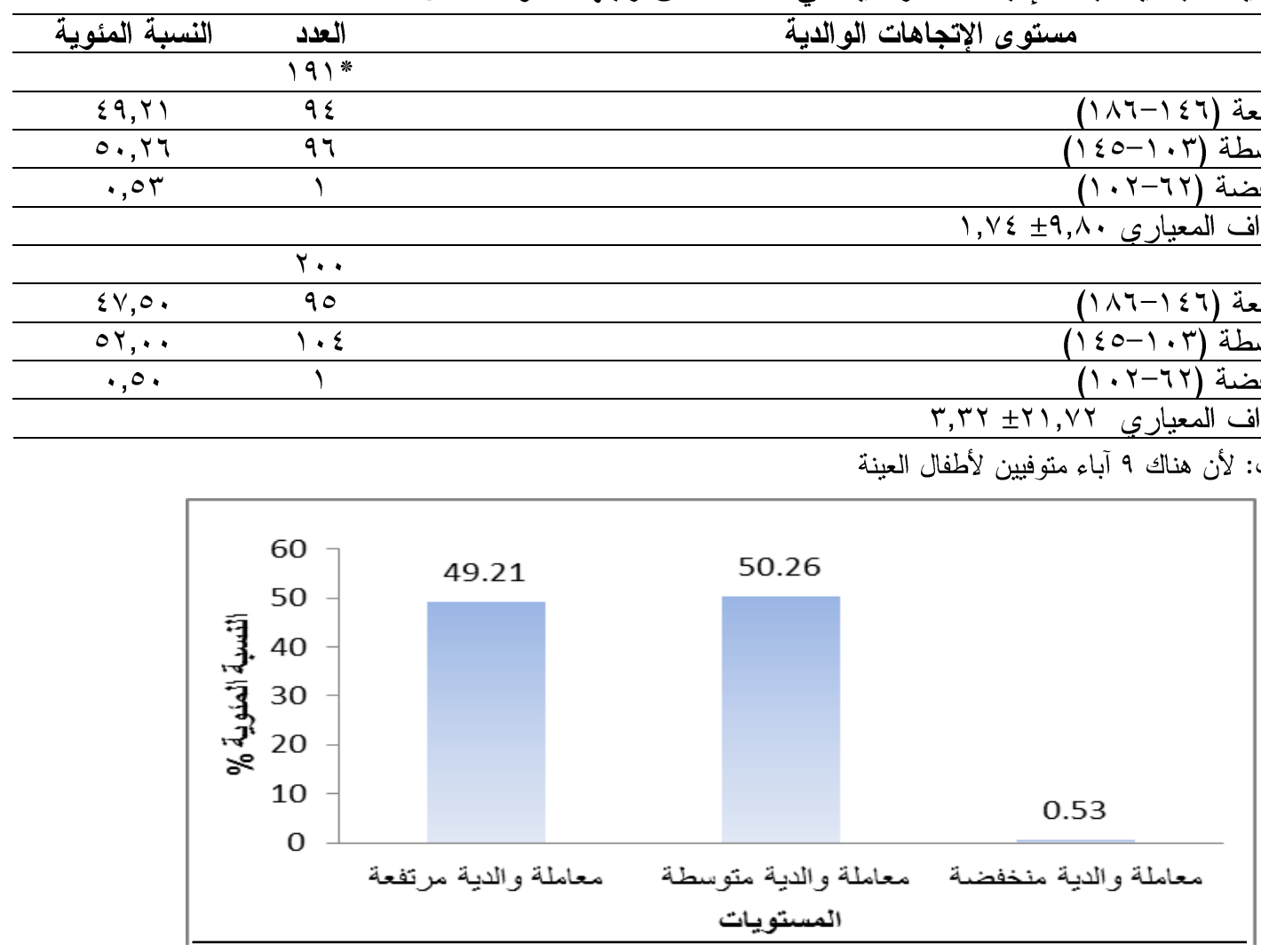

شكل هـ توزيع العينة البحثية تبعاً لمستويات الاتجاهات الوالدية(صورة الأب) 
مجلة الإسكندرية للتبادل العلمى - (مجلد Tr العددץ) يوليو - سبتمبر 17 • ب

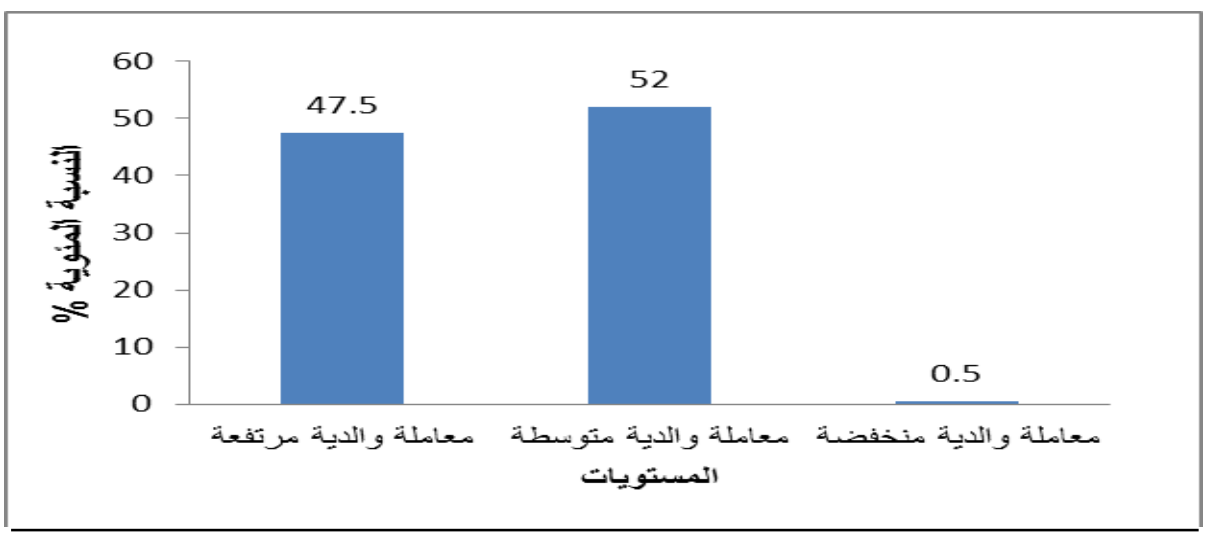

شكل ا. توزيع العينة البحثية تبعاً لمستويات الاتجاهات الوالدية(صورة الأم)

جدول ج. العلاقة الارتباطية بين الخصائص الثخصية والأسرية للطقل كمتغير مستقل وتقدير الأت كمتغير تابع تقدير الذات

\begin{tabular}{|c|c|c|c|c|c|c|}
\hline \multicolumn{6}{|c|}{ تقدير الذات } & \multirow{2}{*}{ الخصائص الثخصية والأسرية } \\
\hline الكلي & الكفاءة الذاتية & الرضا عن الذات & المدرسي & الإجتماعي & الجسمي & \\
\hline$\cdot, \cdot 1$ & $\cdot, 1 \mu$ & $-\cdot, \cdot 1$ &.,- .0 &.,$- \cdot 1$ & $\cdot, 0$ & الطفل \\
\hline$-* *, Y$, &.,- .0 &.,- 11 & $* *-, Y, Y V$ & $-*,, I V$ &.,$- \cdot Y$ & جنس الطفل \\
\hline.,- .0 &,.,$- \ldots \varepsilon$ &.,$\ldots \Lambda$ &.,- .0 &.,$- \cdot V$ & $\cdot, \cdot r$ & السنة الدر اسبة \\
\hline.,$- \cdot 7$ &., .0 & $-\cdot, \cdot r$ & $\cdot, \cdot r$ & $\cdot, \cdot 1$ &.,$- \ldots \varepsilon$ & نو ع المدر سة \\
\hline$-, \cdot, r$ &,,$- \ldots r$ &., .9 &.,- .9 &.,$- \cdot 1$ &., .0 & تر تتب إلمبلاد \\
\hline.,$- \cdot \mathrm{V}$ & $\cdot, \cdot 1$ & $-\cdot, \cdot r$ & $-* *, 1 \leq$ &.,$- \cdot r$ &.,$- \cdot \pi$ & عمر الأب \\
\hline$*,, 1 \leqslant$ & $\cdot, \cdot V$ &., .0 &., .7 & $\cdot, \cdot 7$ & $* ., 17$ & المستوى التعليمي للأب للأب \\
\hline$-* ., 17$ & $-*, 17$ & $-\cdot, \cdot 1$ &., 1 & $-* *, 1 \leq$ & $-, \cdot, 1$ & عمل الأب \\
\hline., .0 & $\cdot, \cdot \varepsilon$ & $-\cdot, \cdot \varepsilon$ & $\cdot,+r$ &.,$\ldots 1$ & $\cdot, 1 \mathrm{r}$ & مينة الأب \\
\hline.,- 11 & $-\cdot, \cdot \varepsilon$ &.,$- \cdot 7$ & $-* *, r$. &,,$- \cdot \varepsilon$ &.,- 0 & عمر الأح \\
\hline$\cdot, \cdot \varepsilon$ & $\cdot, \cdot 1$ & $\cdot, \cdots 9$ & $-\cdot, \cdots \varepsilon$ & $\cdot, .0$ & $\cdot, 1 T$ & المستوى التعليمي للأم \\
\hline$\cdot, \cdot 1$ &., .9 & $\cdot, 0$ &., .9 & $\cdot, \cdot V$ &., .9 & عمل الأح \\
\hline$\cdot, 0$ & $\cdot, \cdot V$ & $\cdot, \cdot \varepsilon$ &., .1 &.,$- \cdot 1$ &., .7 & عدد أفر اد الأسرة \\
\hline$-\cdot, \cdot \wedge$ & $\cdot, .0$ & $\cdot, .0$ & $-\cdot, \cdots 4$ & $-\cdot, \cdot \wedge$ & $-\cdot, \cdot r$ & التز احم الحجري \\
\hline
\end{tabular}

ب- العلاقة الإرتباطية بين الخصائص الثخصية والأسرية وتقدير الأات الإجتماعي:

تشير البيانات الواردة أيضاً بجدول(آ) إلي وجود علاقة

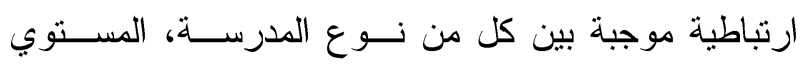

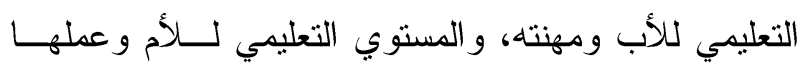
كمتغير ات مستقلة وبين تقدير الذات الإجتماعي كمتغير تابع. كما تبين وجود علاقة ارتباطية سالبة بين كل من عمر

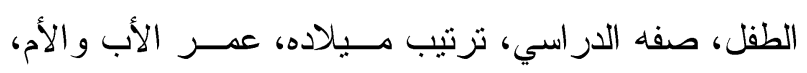

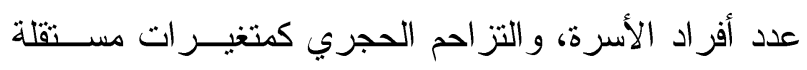
وبين تقدير الذات الإجتماعي كمتغير تابع.
كما تبين أن هناك علاقة إرتباطية سالبة بين كـلـ مــن

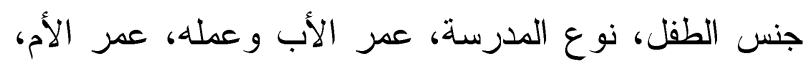

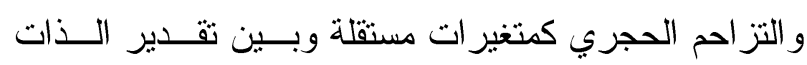
الجسمي كمتغير تابع. كما تبين أن هنالك علاقة إيجابية معنويــة عنــــ مســتوي (0. • •) بين المستوي التعليمي للأب كمتغير مستقل وتقدير الذات كمتغير تابع. 
مستوي تعليم الأب و الأم ومهنتهما، فكلمــا زاد المســتوي

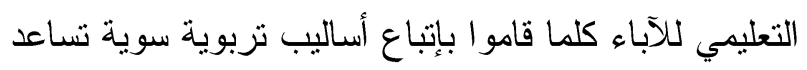

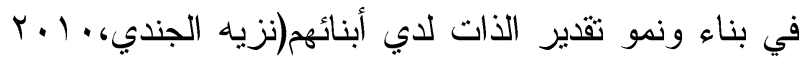

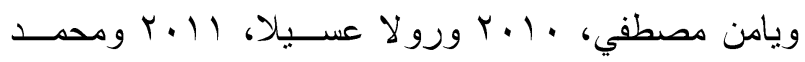

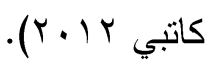

و أيضًاً علاقة إرتباطية معنوية ســالبة عنــد مســتوي (0. (•) بين عمل الأب كمتغير مستقل وتقدير الذات الكلي كتغغير تابع، كذلك وجود علاقة إرنباطية معنوية سالبة عند مستوي (1 •, •) بين جنس الطفل كمتغير مســتقل وتقــدير الذات الكلي كمتغير تابع.

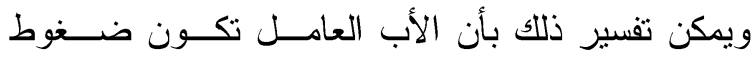

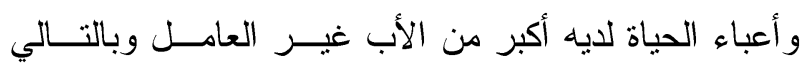

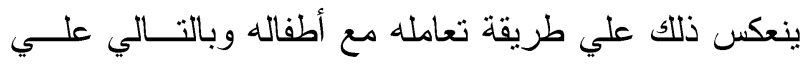
تقدير الذات لديهم. كما تبين وجود علاقة ارتباطية سالبة بـين كــل مــن، الصف الدراسي، نوع المدرسة،ترنيب الميلاد، وعمر الأب، عمر الأم، ودرجة التزاحم الحجري كمتغيرات مستقلة وبين تقدير الذات الكلي كمتغير تابع.

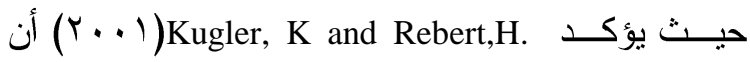
ضغوط الحياة اليومية علي الوالدين و الناتجة عن كبر سنهم

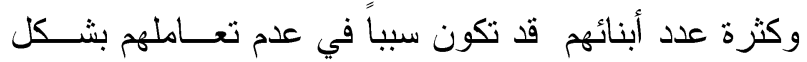
مناسب مع أبنائهم مما يؤثز علي تقديرهم لذو اتهم.

\section{r.العلاقة الإرتباطية بين درجة الإساعة التي يتعرض لهــا} الأطفال كمتغير مستقل وبين تقدير الأت كمتغير تابع: يثير جدول(V) أن هناك علاقة ارتباطية سالبة جوهرية عند مستوي (1 +, ·) بين درجة الإساءة الجسدية و اللفظيــة

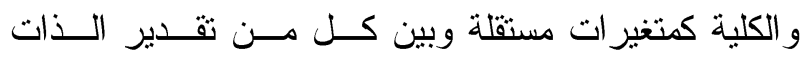
الجسمي، الإجتماعي، المدرسي، الكفاءة الذاتية،وتقدير الذات الكلي كمتغير ات تابعة.
وتبين أيضاً وجود علاقة إرتباطية سالبة معنويـــة عنـــد

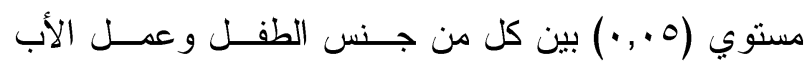
كمتغير ات مستقلة وبين تقدير الذات الإجتماعي كمتغير تابع. ج- العلاقة الإرتباطية بين الخصائص الشخصية والأسرية وتقدير الأات المدرسي:

تشير البيانات الواردة أيضاً بجدول(7) إلي وجود علاقة

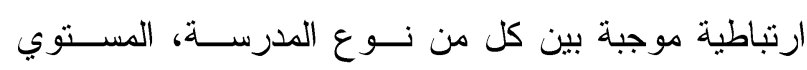
التعليمي للأب و عمله ومهنته، عمل الأمهو عدد أفراد الأسرة كمتغيرات مستقلة وبين تقدير الذات المدرسي كمتغير تابع. كما تبين وجود علاقة ارتباطية سالبة بين كل من عمر الطفل، صفه الدراسي، ترتيب ميلاده، المستوي التعليمـي لئي للأم، و التزاحم الحجري كمتغيرات مستقلة وبين تقدير الذات المدرسي كمتغير تابع.

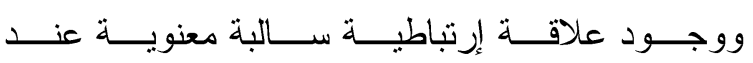

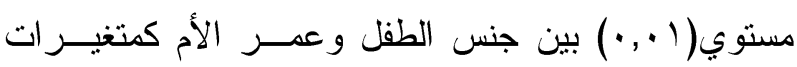
مستقلة وبين تقدير الذات المدرسي كمتغير تابع. كذلك تبين وجود علاقة إرتباطية معنوية ســالبة عنــد مستوي(0 •., ) بين عمر الأب كمتغير مستقل وبين تقـدير الذات المدرسي كمتغير تابع. 7- العلاقة الإرتباطية بين الخصائص الثخصية والأسرية وتقدير الأات الكلي:

تشير البيانات الواردة أيضاً بجدول(7) إلي وجود علاقة

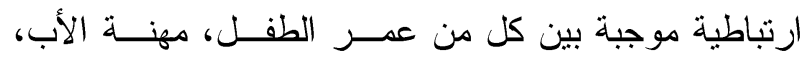

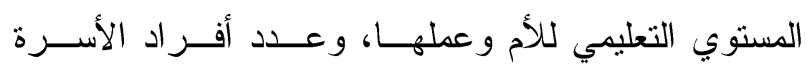
كمتغيرات مستقلة وبين تقدير الذات الكلي كمتغير تابع.

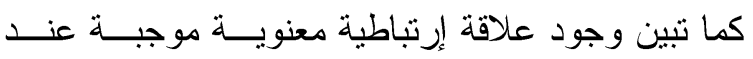
مستوي(0 •., ) بين تعليم الأب كمتغير مستقل وتقدير الذات الكلي كمتغير تابع. ويفسر ذلك بأن للو الدين و البيئة الأسرية أهمية كبيرة في بناء شخصية أبنائهم وزيادة تقدير هم لذو اتهم وذلك يتمثل في ولي 
مجلة الإسكندرية للتبادل العلمى - (مجلد Tr العددץ) يوليو - سبتمبر 17 • ب

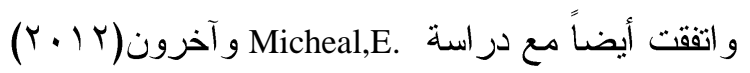
و التي هدفت إلي التعرف علي آثار الإساءة التي يتعـرض

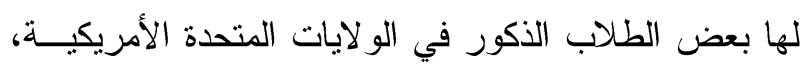
وقد أسفرت النتائج أن من أهم آثار التعرض للإساءة هـي لإليات

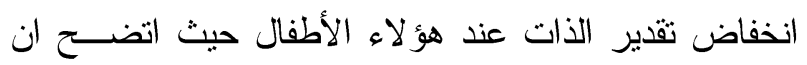
هناك علاقة ارتباطية عكسية بين مستوي التعرض للإساءة

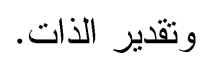
و اتفقت أيضناً مــع در اســة Arslan,S. أجريت في تركيا،حيث أوضح أن هناك علاقة سالبة بـين دين تعرض الأطفال للإساءة النفسية و المعنوية وبين مســتوبي تقدير الذات لديهر.

r.العلاقة الإرتباطية بين الإتجاهات الوالدية في التتشـئة

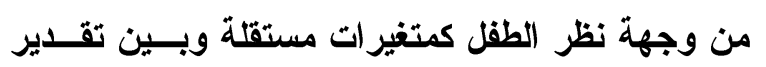
الأت كمتغير تابع:

تشير البيانات الواردة بجدول(^) إلي وجــود علاقــة إرتباطية موجبة بين كل من الإتجاهات الو الدية في التنشـئة

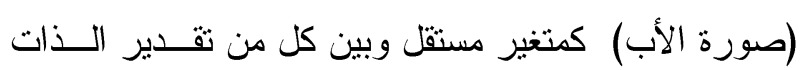

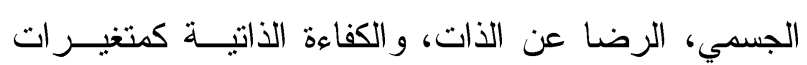

كما يوجد علاقة إرتباطية سالبة بـين درجـة الإســـاءة الجسدية و اللفظية كمتغيرات مستقلة وبين الرضا عن الذات، و علاقة ارتباطية سالبة جوهرية عند مستوي( و .,.) بـين

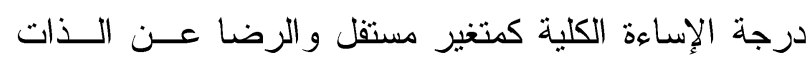
كمتغير تابع.

بمعني أنه كلما زاد مستوي الإساءة التي يتعرض لهـا

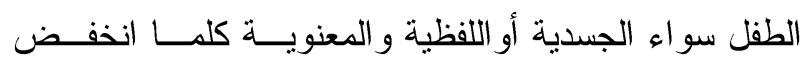

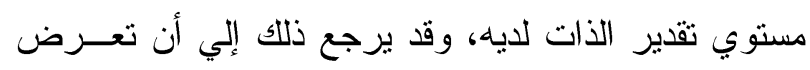
الطفل للإساءة قد يؤدي إلي انخفاض مستوي ثقته في نفسه

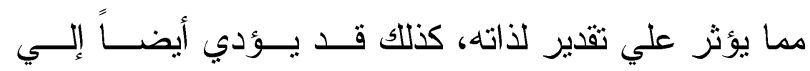
انخفاض احتر امه لذاته وسط الآخرين. Alina, M and وتتفق نتائج هذه الدر اسة مــع در اســـة Simon, E التعرف علي تأثير تعرض الأطفال في مرحلة الطفولة علي تقدير هم لذو اتهم في مرحلة المراهقة، وقد اتضح من خلال

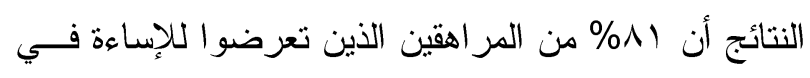

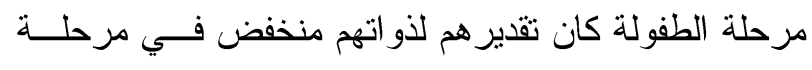
المر اهقة. - اهـ تابعة.

جدول V. العلاقات الارتباطية بين درجة الإساءة الموجهة للطفل كمتغير مستقل وبين تقدير الذات كمتغير تابع

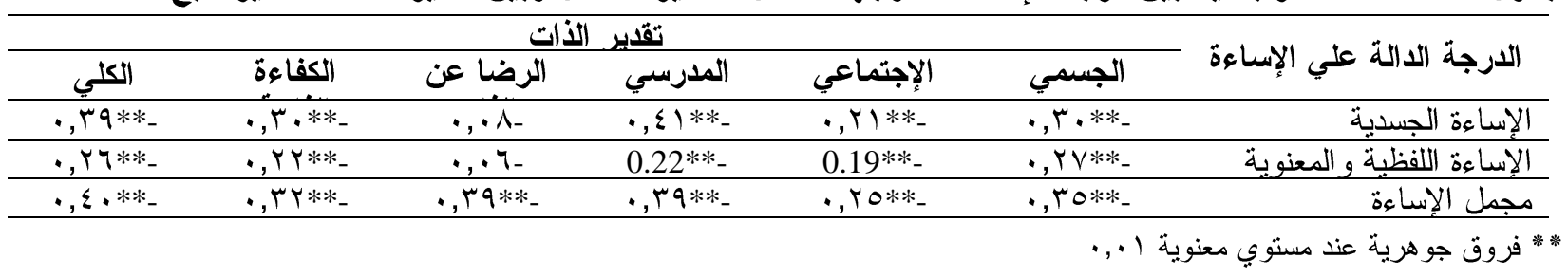

جدول ^. العلاقات الارتباطية بين الإتجاهات الوالاية في التنشئة كمتغير مستقل وبين تقدير الأات كمتغير تابع

\begin{tabular}{|c|c|c|c|c|c|c|}
\hline \multicolumn{6}{|c|}{ تقدير الذات } & \multirow{2}{*}{ الإتجاهات الو الدية } \\
\hline الكلي & الكفاعة & الرضا عن & المدرسي & الإجتماعي & الجسمي & \\
\hline$*, 1 \leq$ & $\cdot, \cdot \wedge$ & $\cdot, \cdot \varepsilon$ & $* * \cdot, 1 \wedge$ & $* ., 10$ & $\cdot, \cdot V$ & (صورة الأب) \\
\hline$* * \cdot, Y$ & $\cdot, \cdot 7$ & $\cdot, 1$. & $* *, Y 0$ & $* * \cdot, Y I$ & $* *, Y Y Y$ & (صورة الأم) \\
\hline
\end{tabular}




\section{التوصيات}

في ضوء النتائج التي أسفرت عنها الاراسة بمكن التوصل إلىي التوصيات الآتية:

1- ضرورة توعية الآباء والأمهات بآثار الإساءة للطفــل

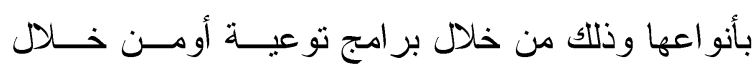

$$
\text { وسائل الإعلام المختلفة. }
$$

r- حث الآباء والأمهات علي إتباع الإتجاهـات الو الأيسـة

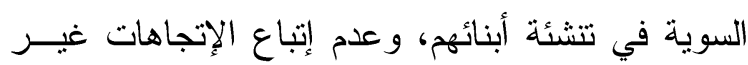
السوية.

ب- ضرورة تعاون كل من الددرسة و الو الدين فـي تتميــة تقدير الأطفال لذو اتهم.

ع- التأكبد علي دور الاقتصاد المنزلي في نشر المعلومات

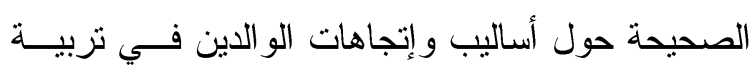

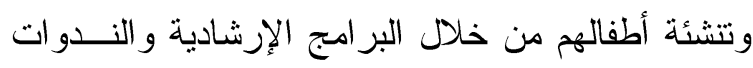
و والدور ات التدريبية للأمهات.

\section{المــراجـع}

أماني عبد المقصود ا ـ r، مقياس أساليب المعاملة الو الدية، مكتبة الأنجلو ، القاهرة، جمهورية مصر العربية.

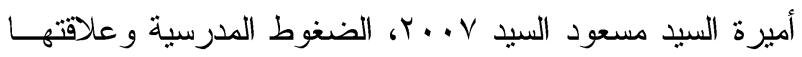

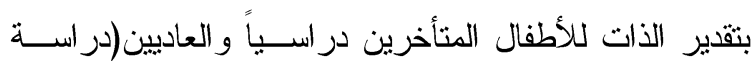
مقارنة)، رسالة ماجستير ، كلية التربية، جامعة الزقازيق.

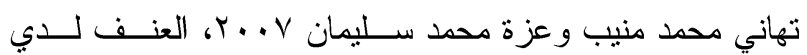
الثباب الجامعي،جامعتنايف العربية للعلوم الأمنية، المملكـــة

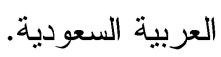

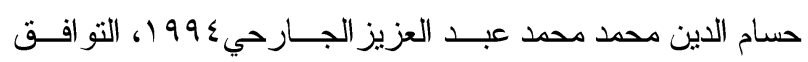

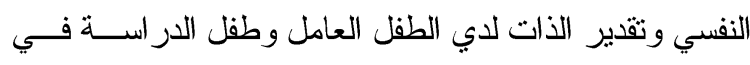
الريف، رسالة ماجستير، قسم الدر اسات النفسية و الإجتماعية،

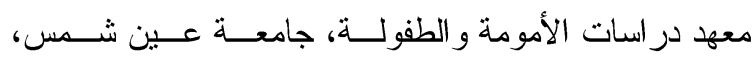

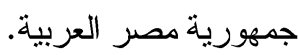

كذللك وجود علاقة إرتباطية موجبــة بـين كــل مـن الإتجاهات الوالدية في التنشئة(صورة الأم) كتنغير مستقل وبين الرضا عن الذات و الكفاءة الذاتية كمتغيرات تابعة.

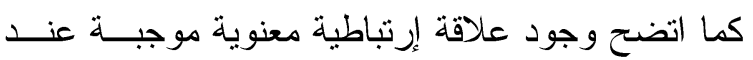
مستوي معنوية(0., •) بين كل من الإتجاهات الو الدية فــي

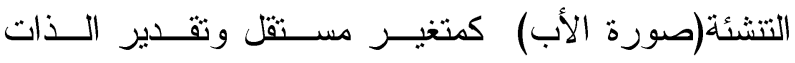
الإجتماعي وتقدير الذات الكلي كتنغيرات تابعة.

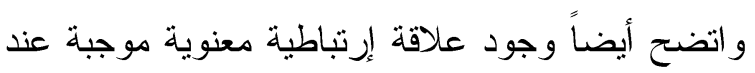

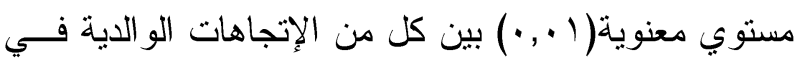

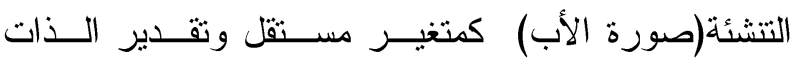

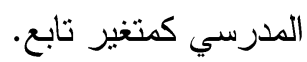
وعلاقة إرتباطية معنوية موجبة عند مســتوي معنويــة

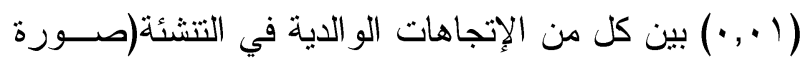

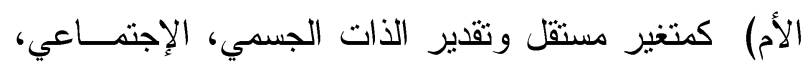
الدرسي، و الكلي كمتغير ات تابعة.

بمعني أنه كلما كانت الإتجاهات الو الدية التي بستخدمها

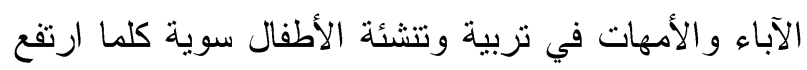
مسنوي تقدير الذات عند الطفلويمكن تفسير ذلك بأنه عندما يكون هناك كنوير

اتفاق وتوازن بين آراء الآباء والأمهات دون إفــر اط أو تفريط في عملية تربية وتنشئة الأبناء ،فــن خـلاهل هـــا

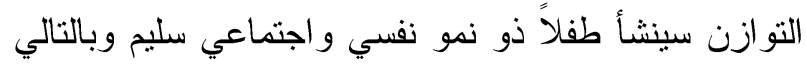

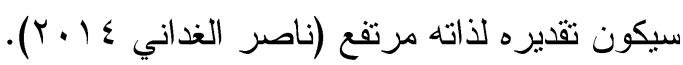
Blattner ,M. وتنقق نتائج الدراسة الحالية مع ما وجده

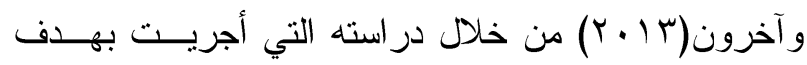

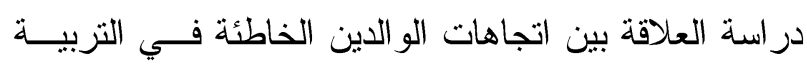

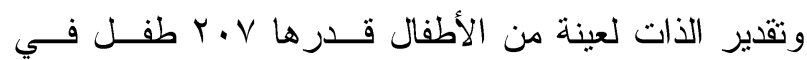

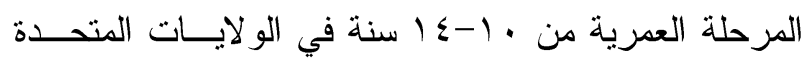

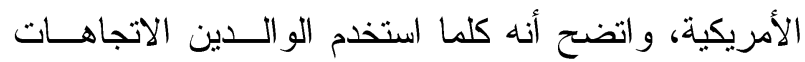
الخاطئة كلما انخفض مستوي تقدير الذات لاي الأبناء. 


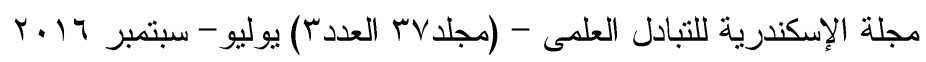

مروة محمد الخطيب |1 +.r، العنف الأسري ضد الطفل وعلاقته بمتغيرّي جنس الطفل و المستوي التعليمي للو الــدين، مجلـــة

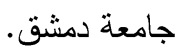

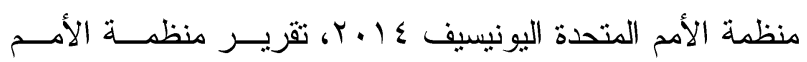
المتحدة، تحليل إحصائي للعنف ضد الأطفال.

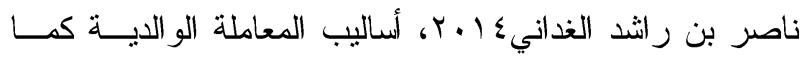

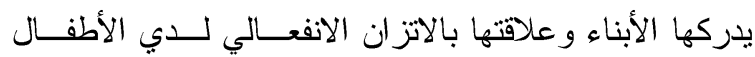

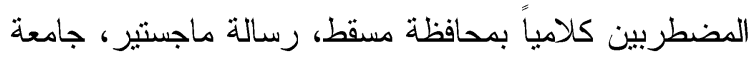

$$
\text { نزوي، كلية الآداب، عمان. }
$$

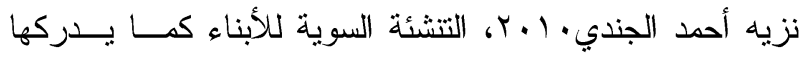
الو الدان في الأسرة العمانية، مجلة جامعة دمشق.

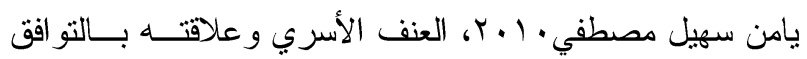
النفسي لدي المر اهق، رسالة ماجستير ، كلية التزبية، جامعسـة ولنة دمشق.

Alina, M. and E. Simon. 2012. Abused Children's SelfEsteem . J. Soc. Beha. Sci. 46: 4580-4584.

Arslan, G. 2016. Psycological Maltreatment, Emotional And Behavioral Problems In Adolesents: The Mediating Role of Resilience and Self- Esteem. J. Child Abuse Neg. 52: 200-209.

Blattner, M. B.Liang,T. Lund, and R.Spencer. 2013. Searching For A Sense of Purpose: The Role of Parents and Effects On Self-Esteem Among Female Adplescents. J. Adolescence, 36: 839-848.

Duncan,A. C.Sartor, M. Reid, and A.Heath. 2015. Association Between Body Mass Index, Post- Traumatic Stress Disorder, And Child Maltreatment In Young Women. J.ournal Child Abuse Neg. 45: 154-162.

Gooding, H., C.Milliren, B. Austin, and M. Sheridan. 2015.Exposure To Violence In Childhood Is Associated With Higher Body Mass Index In Adolescence . J.ournal Child Abuse Neg 50:151-158.

Kiser,L.,C. Stover,C. Navalta, and R.Lee. 2014. Effects of Child - Perpetrator Relationship On Mental Health Outcomes Of Child Abuse: It's (Not) All Relative . J.ournal Child Abuse Neg 38:1083-1093.

Kugler, K and H. Rebert. 2001. Relational Competence and Social Shpport Among Parenta At Risk of Child Abuse. Family Relations Journal. National Council Family Relations. PP328- 332.

Marije, S., M. Kranenburg, A. Lenneke, and H. Marinus. 2015. The Prevalencce of Child Maltreatment Across The Globe. Child Abuse Review 24:37-50.

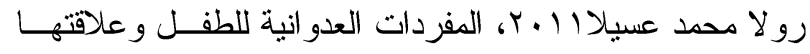

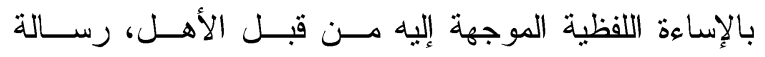

$$
\text { ماجستير ، كلية التربية، جامعة دمشق. }
$$

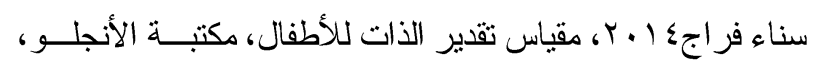
القاهرة، جمهورية مصر العربية.

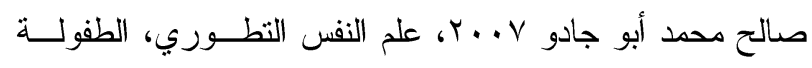
و المر اهقة، الطبعة الثانية، دار المسيرة للنشر، سلطنة عمان.

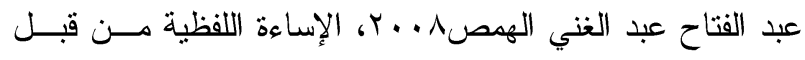
الو الدين ضد الأطفال المعوقين وعلاقتها بالتوافق النفسي في لإني

البيئة الفلسطنية، كلية التربية، الجامعة الإسلامية، غزة.

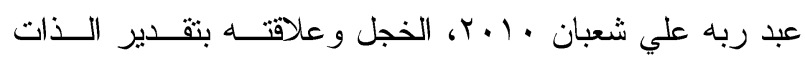

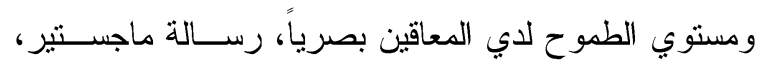

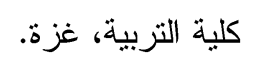

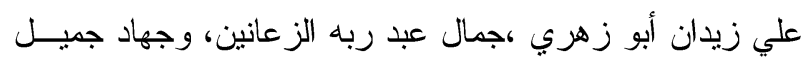

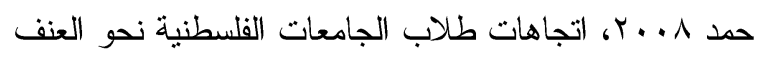
ومستوي ممارستهم له مجلة جامعة الأقصي، المجلد الثـاني عشر، العدد الأول، جامعة الأقصي.

عماد مخيمر و عماد عبد الرازق ب ا ـ r، مقياس الإساءة الموجهة للطفل، مكتبة الأنجلو، القاهرة، جمهورية مصر العربية.

فاروق موسي ومحمد دسوقي999 (99، مقياس تقدير الذات، مكتبــة

$$
\text { الأنجلو، القاهرة، جمهورية مصر العربية.. }
$$

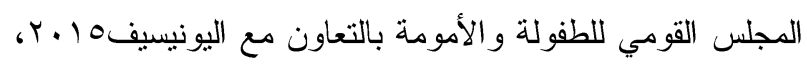

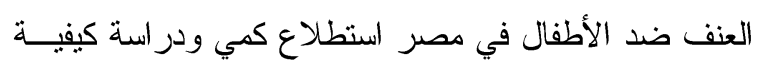

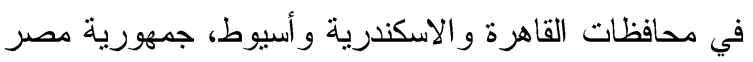
العربية.

محمد السيد عبد الرحمن ومني خليفــة حسـن r . . r، تــدريب الأطفال ذوي الاضطر ابات السلوكية علي المهارات النمائية،

$$
\text { دار الفكر العربي، الطبعة الأولي. }
$$

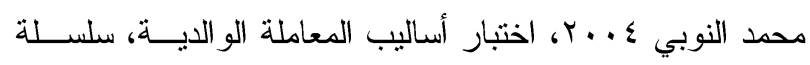

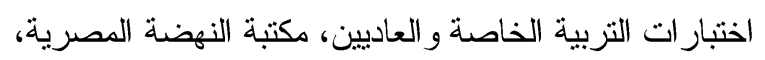

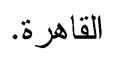

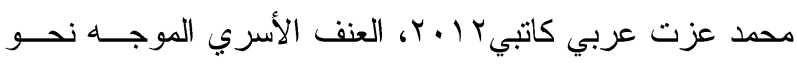
الأبناء و علاقته بالوحدة النفسية، مجلة جامعة دمثق. 
Ross, A ., J. Dion, M.Cantinotti,D. Vezina, and L. Paquette. 2015. Impact of Residential Schooling And Child Abuse On Substance Use Problem In Indigenous Peoples. J. Add. Beh.51:184-192.

Stevens, K., J. Schneiderman, S. Negriff, A. Brinkmann, and P.Trickett. 2015. The Whole Picture: Child Maltreatment Experience of Youths Who Were Physically Abused. J.ournal Child Abuse Neg 43: 30-41.
Michael, E., S.Woolley, and J. Sung. 2012. Exposure To Violence, Student Fear, And Low Academic Achievement: African Amercan Males In The Critical Transition To High School. J. Chil. Youth. 34: 388-395.

Potthast, N., F. Neuner, and C.Catani. 2015. When Abuse Primes Addiction- Automatic Activation Of Alcohol Concepts By Child Maltreatment Related Cues In Emotionally Abused Alcoholics. J.Add. Beh.48: 62-70.

Ramadan, S., N. Mostafa, S.Mahmoud, and H.Abdel Hakim. 2007. Professional Workers Knowledge, Attitude And Performance Toward Child Abuse Among Governmental Primary Schools. The Med. J. Cairo Uni.vol 75.

\title{
ABSTRACT \\ Factors Related To Self - Esteem among a Sample of Children in Late Childhood Stage
}

\author{
Doaa F.A. Aosman, Lila M.Al-khadary, Ahamed S.Abo Donia
}

The present study aimed to investigate Factors Related To Self- Esteem Between A Sample Of Children In Late Childhood Stage, the sample Included 200 children in late childhood stage. Data were collected through personal interview questionnaire with children.

The most important results could be summarized as follows:

For personal and household characteristics:

1- The age of $58.5 \%$ of fathers ranged between $40->$ 50 years, and the age of $56.5 \%$ of the mothers ranged in age from $30 \rightarrow 40$ years.

2- $26 \%$ of fathers and $22 \%$ of mothers had High level education.

3- $53.5 \%$ of fathers were working acts literal and $78 \%$ of mothers were house wives.

4- $65 \%$ of children were ranged number of family members between 4-5.

- the results revealed that, $73 \%$ of the children exposed to physical abuse ranged to severe, medium and weak $(1.37 \%, 10.96 \%, 87.67 \%)$, respectively.
- the results revealed that all of children's sample were exposed to verbal and emotional abuse ranged between severe, medium, and weak levels $(1 \%, 40 \%$, $59 \%)$.

- the results showed that $50.26 \%$ and $52 \%$ of children have received moderate levels in the overall trends in parental upbringing.

- for the level of self-esteem the results shown that $57.5 \%$ of children had moderate level.

- The results of the correlation coefficients of some variables indicated that there was a positive significant correlation $(\mathrm{P}<0.01)$ between child gender and self - esteem, and a negative significant correlation $(\mathrm{P}<0.05)$ between mother work and self esteem. Also a positive significant correlation $(\mathrm{P}<0.05)$ between educational status of fathers and self - esteem.

- Also, there was a negative highly significant correlation $(\mathrm{P}<0.01)$ between physical, verbal, and totally abuse and self - esteem.

- The results revealed, that there was positive significant correlation $(\mathrm{P}<0.05)$ between the parenting trends father's figure and self - esteem, and positive significant correlation $(\mathrm{P}<0.01)$ between the parenting trends mother's figure and self - esteem. 